\title{
Which Way Forward for Macroeconomics and Policy Analysis?
}

\author{
Roman Frydman and Edmund S. Phelps
}

There was a palpable sense of excitement among the economists who met in Philadelphia in 1969 at the conference organized by Edmund Phelps. Their research over the preceding years had coalesced into a new approach to macroeconomic analysis, one that based macrorelationships on explicit microfoundations. These foundations' distinctive feature was to accord market participants' expectations an autonomous role in economists' models of aggregate outcomes. The conference contributions, published in what came to be known as "the Phelps microfoundations volume" (Phelps et al. 1970), provided radically new accounts of the comovements of macroeconomic aggregates-notably, inflation and unemployment. They also cast serious doubt on the validity of policy analysis based on then-popular Keynesian macroeconometric models.

The Phelps volume is often credited with pioneering the currently dominant approach to macroeconomic analysis. Indeed, it is easy to see why today's prevailing models of aggregate outcomes might seem to share much with their counterparts in the Phelps volume. Like their predecessors in the late 1960s, economists today often point to their models' "microfoundations" as their essential feature. Moreover, in modeling decisionmaking, these microfoundations include a representation of market participants' expectations. However, on closer inspection, the similarities between today's models and those included in the Phelps volume are purely linguistic.

The authors thank the Alfred P. Sloan Foundation for its support of the Center on Capitalism and Society's 8th Annual Conference, at which the papers published in this volume were originally presented. Ned Phelps acknowledges the Ewing Marion Kauffman Foundation's support for his research, and Roman Frydman is grateful to the Institute for New Economic Thinking (INET) for its support of his work on Imperfect Knowledge Economics. The authors are indebted to Michael Goldberg for his invaluable comments on a previous draft of this chapter. 
In the early 1970s, just a few years after the Phelps volume was published, economists began to embrace the Rational Expectations Hypothesis (REH), according to which market participants' expectations are "essentially the same as the predictions of the relevant economic theory" (Muth 1961: 316). What has been largely overlooked is that, in contrast to the contributors to the Phelps volume, REH theorists presume that the role of market participants' expectations in driving outcomes is not autonomous from the other components of the model. As one of the pioneers of the REH approach succinctly put it: "in rational expectations models, people's beliefs are among the outcomes of [economists'] theorizing. They are not inputs" (Evans and Honkapohja 2005: 566). Because REH models, by design, rule out an autonomous role for expectations, they are best viewed as derailing, rather than developing, the microfoundations approach.

Early critics pointed out REH's fundamental epistemological flaws (see Frydman 1982, 1983; Frydman and Phelps 1983; Phelps 1983). They argued that REH, even if viewed as a bold abstraction or approximation, is grossly inadequate for representing how even minimally reasonable profitseeking participants forecast the future in real-world markets. Nevertheless, for various reasons (some of them discussed in this volume), an overwhelming majority of economists has embraced REH as the way to represent how rational individuals think about the future.

The epistemological flaws inherent in REH models have, not surprisingly, resulted in serious empirical difficulties, despite decades of "fine-tuning." As one of us recently commented, "the stampede toward 'rational expectations,' widely called a 'revolution,' though it was only a generalization of the neoclassical idea of equilibrium . . . has not illuminated how the world economy works" (Phelps 2007: xv).

Nowhere have REH's epistemological flaws and empirical disappointments been more apparent than in efforts to model financial market outcomes, which are largely driven by participants' expectations. Beginning with Robert Shiller's (1981) pathbreaking paper, research has shown that $\mathrm{REH}$ models are unable to explain the basic features of fluctuations and risk in stock markets. Likewise, in their magisterial work on the current state of international macroeconomics, Maurice Obstfeld and Kenneth Rogoff (1996: 625) concluded that "the undeniable difficulties that international economists encounter in empirically explaining nominal exchangerate movements are an embarrassment, but one shared with virtually any other field that attempts to explain asset price data."

The failures of REH explanations of aggregate outcomes gave rise to alternative approaches, most notably behavioral finance models. However, sober assessments even by the likes of Obstfeld and Rogoff did not dispel the faith of most economists that REH models would one day be able to explain financial market outcomes and macroeconomic performance. 
Indeed, in the wake of the crisis that began in 2007, most economists continue to seek modifications of REH models that would remedy their empirical failures. However, by highlighting the irredeemable shortcomings of so-called rational market models, the crisis has led many researchers to join the quest to develop alternatives to REH.

So, what comes next? Although many more researchers now seem to agree that we need new approaches to macroeconomics and finance theory, the way forward has not been easy to discern. This is to be expected during a time of transition away from an approach that for decades has virtually monopolized the education and thinking of professional economists.

To be sure, the proposed alternatives differ in important respects from the approach promoted in the Phelps volume. But the recent flurry of theoretical efforts has been notable for approaches that in one way or another bring us back to the major theme of the original Phelps conference: nonREH modeling of market participants' expectations and their active role in driving aggregate outcomes. The new models have led to reconsideration of some of the main applied problems that occupied the participants in the Phelps conference and subsequent REH researchers: explaining employment fluctuations, modeling the natural rate of unemployment, and investigating the consequences of economic policy.

In view of the financial crisis, recent research efforts have also been focused on closely related themes: understanding the role of expectations in modeling fluctuations in asset prices and risk, and representing the twoway interdependence between asset markets and the real economy. The crisis has also demanded reconsideration of the theory and practice of economic policy.

With that in mind, in the fall of 2010, the Center on Capitalism and Society invited researchers engaged in developing alternatives to REH to a conference commemorating the fortieth anniversary of the Phelps volume. In this introductory chapter, we provide a brief, admittedly idiosyncratic discussion of the papers presented, the historical background, and the various efforts to reinvent macroeconomics that were discussed at the conference. In view of the central role played by autonomous expectations in the contributions to the Phelps volume, this overview devotes attention particularly to non-REH alternatives - many of which are represented in this volume-and their implications for economic analysis.

\section{A Research Program Derailed}

Even cursory observation indicates that how market participants in a modern economy think about the future and revise their forecasts is one of the crucial factors driving their decisionmaking (and thus outcomes) in many 
markets. Implementing a formal approach to macroeconomic analysis that is based on individual decisionmaking requires, therefore, that an economist represent participants' forecasting behavior mathematically. In discussing his vision for the microfoundations approach, Phelps et al. (1970: 22) underscored the fundamental difficulty in portraying individuals' expectations: "isolated and apprehensive, these Pinteresque figures construct expectations of the state of the economy .... and maximize relative to that imagined world."

The papers presented at the Phelps conference did not attempt to formalize market participants' "imagined world." Instead, relying on the so-called adaptive expectations rule, they modeled the forecasting process as an automatic response to forecast errors: participants were assumed to revise up or down their one-period-ahead forecast of, say, inflation by a fixed proportion of the error between the realization of inflation in the current period and the previous period's inflation forecast.

Nearly a decade prior to the Phelps conference, John Muth (1961) criticized such error-correcting rules. He argued that they assume away an important consideration: in forming expectations, market participants take into account their understanding of the causal process driving the outcomes that they are attempting to forecast. He proposed REH as a way to represent market participants' "imagined world"- their understanding of the economy and how they use this understanding in forecasting outcomes.

Attendees at the 1969 conference were aware of REH. However, the models that they developed for the Phelps volume did not make use of it; indeed, REH did not even appear in the index. This was consistent with Muth's caveat that, despite its name, the hypothesis was not intended to represent how participants should forecast the future. As he put it: "At the risk of confusing this purely descriptive hypothesis with a pronouncement as to what firms ought to do, we call such expectations 'rational'" (Muth 1961: 316).

To implement REH, an economist must find an economic model to represent participants' understanding of how market outcomes unfold over time. For Muth, whenever an economist formulates a model of the causal process driving outcomes, his own model is "the relevant economic theory." Muth embedded REH in a model of an agricultural market that characterized change with an overarching probability distribution: conditional on its structure, as well as on realizations of the causal variables at any point in time, the model implied a unique probability distribution of participants' forecasts and outcomes at any other point in time.

Over the past four decades, economists have come to agree that only models that generate such "sharp" predictions of change should be considered "the relevant economic theory." As Roman Frydman and Michael Goldberg argue in Chapter 4 of this volume, it is this conception of eco- 
nomic science that led economists to embrace REH as the only valid way to model how rational, profit-seeking market participants forecast the future.

\section{"Rational Expectations" versus Nonroutine Change}

To construct a model that generates sharp predictions of change, an economist must fully and simultaneously specify how participants' forecasting strategies and the causal process driving market outcomes unfold between any two points in time-past, present, and future. This requires that an economist assume that nonroutine change-change that cannot be specified in advance with mechanical rules and procedures that are programmable on a computer-is unimportant for understanding outcomes.

Muth's model provides a particularly simple example of such fully predetermined models. He constrained his model's structure-its functional form and the properties of the causal variables, as well as the parameters relating them to outcomes-to be unchanging over time. Such a timeinvariant structure in effect assumes that market participants do not change the way that they make decisions, and that the process driving prices and other market outcomes also remains unchanged over time.

Economists subsequently recognized that, as time passes, participants do indeed revise their forecasting strategies and alter the way in which they make decisions. Moreover, the social context and the causal process underpinning market outcomes also change over time. Nevertheless, economists' insistence that their models generate sharp predictions trumped the importance of nonroutine change, leading them to represent decisionmaking and the process underpinning the causal variables with mechanical rules and procedures.

A particularly influential class of such models uses several time-invariant structures to characterize forecasting strategies and market outcomes during different time periods. These models represent change with a probabilistic Markov rule that governs switches between the assumed structures, or "regimes." But, because they fully specify both the process governing change and the post-change representation of outcomes in advance, these models share a key property with their time-invariant counterparts: they describe change with an overarching probability distribution in which the set of outcomes and their associated probabilities are fully predetermined in all time periods_-past, present, and future.

\section{Rationality as Model Consistency}

By the 1980s, the vast majority of the economics profession embraced the belief that any fully predetermined model could be used to represent how rational market participants forecast the future: an economist had only to 
impose consistency between his model's predictions on the individual and aggregate levels.

This belief seems puzzling: why would the predictions of a particular economist's overarching account have any connection with how profitseeking participants forecast outcomes in real-world markets?

There are no doubt complex reasons for why a group of thinkers or scientists comes to embrace a common belief. But such a coalescence of views around a controlling idea-in this case, the idea that economic analysis can provide a universal procedure for representing how rational individuals forecast the future-often involves tacit acceptance of one or more false premises. In Chapter 4 of this volume, Frydman and Goldberg trace the profession's belief in the efficacy of REH representations to the assumption (and presumption) that economists can discover an overarching account of change in capitalist economies.

Lucas (2001) articulates a story that has been invoked time and again during the past four decades to support the claim that, by imposing consistency on his model, an economist can adequately capture how rational market participants understand the economy. He observed that when an economist formulates an overarching model of market prices, he supposes that it provides an adequate account of real-world outcomes, and that, if it did, profit-seeking market participants would discern what the economist already knew. He then observed that in the context of his model, non-REH forecasting rules generate systematic forecast errors. The key to the REH narrative, therefore, was the belief that such errors pointed to obvious, yet unrealized, profit opportunities in real-world markets. As Lucas later emphatically put it, "if your theory reveals profit opportunities, you have the wrong theory" (Lucas 2001: 13) of how “actual prices" unfold over a longer run. ${ }^{1}$

In a leap of faith that transformed macroeconomics and finance for generations, Lucas presumed that the right theory of capitalist economies, which arguably thrive on nonroutine change, is a fully predetermined model that assumes that such change is unimportant. He then argued that, to represent rational forecasting in real-world markets, an economist must remove the systematic forecast errors-unrealized "profit opportunities"-from his model by imposing consistency between its individual and aggregate levels.

From the early 1970s on, Lucas's story gained wide acceptance among macroeconomists and finance theorists, spanning all major schools of

1. Lucas (1986) did acknowledge that non-REH "adaptive theory" might be useful in accounting for shorter run behavior in some contexts. In Lucas (2004: 23), he acknowledged that REH does not "let us think about the US experience in the 1930s or about financial crises and their consequences. . . . We may be disillusioned with the Keynesian apparatus for thinking about these things, but it doesn't mean that this replacement $[\mathrm{REH}]$ apparatus can do it either. It can't." 
thought. Chicago free-market adherents, New Keynesians, asymmetricinformation theorists, and behavioral finance modelers all took the same leap.

\section{The Diversion of Microfoundations Research}

The models presented in the Phelps volume all relied on a time-invariant structure, with an adaptive-expectations rule to portray market participants' forecasting behavior. ${ }^{2}$ By design, these models presumed that participants at least partly ignore systematic forecast errors. As a result, there was substantial tension between these formalizations and Phelps's vision of a microfoundations research program that would portray how, in making decisions, market participants maximize relative to their "imagined world."

This was the state of economic model-building at the time. A modeling strategy that would both preserve an autonomous role for market participants' expectations and approach Phelps's vision had to await further development of the theory and better empirical knowledge of how participants form forecasts in real-world markets.

However, the widely accepted REH narrative suggested a different direction for further development. Because most economists did not question the premise that overarching accounts of outcomes are within reach of economic analysis, inconsistent models-those that made use of non-REH representations of expectations-became "the wrong theory" and were jettisoned. Furthermore, the vast majority of economists, captivated by Lucas's narrative, embraced REH as the right theory.

\section{Part One: Back to the Foundations}

As the epistemological flaws of REH became recognized, and as evidence of REH models' inconsistency with empirical evidence accumulated, some economists returned to modeling expectations as autonomous-as an input rather than an output of their models. But developing a way to represent participants' expectations that could replace REH has remained a daunting problem, which may be why the alternatives have largely adhered to the core tenet of the contemporary approach to modeling, namely, that fully predetermined accounts of outcomes are within reach of economic analysis. This has enabled critics to move forward while avoiding the question of whether the epistemological and empirical difficulties of REH's portrayals of forecasting reveal a fatal flaw in the fundamental precept on which contemporary macroeconomics and finance models rest.

2. The Phelps paper in the conference volume is, strictly speaking, not time invariant, but it does share the property of the time-invariant papers in that it fully determines the consequences of the disturbance for the time-path of employment and inflation. 
From Immanent Critique of REH to Mechanical Learning Models

In Chapter 1 of this volume, Roger Guesnerie discusses one line of criticism of REH: "the failure of economic theory stressed here concerns expectational coordination" (Chapter 1: 51).

REH presumes a special form of expectational coordination, often called the "rational expectations equilibrium" (REE): except for random errors that average to zero, an economist's model- "the relevant economic theory"-adequately characterizes each and every participant's forecasting strategy. Guesnerie's immanent critique is that decentralized markets, in general, will not produce the uniformity among participants' forecasting strategies that REE takes for granted, even in the context of an overarching model.

Eductive Games and Stability Analysis

Guesnerie formalizes the problem by examining whether each market participant would forecast according to an economist's REH model in the context of what he calls an "eductive game." The game assumes that every market participant knows perfectly the structure of the model-its functional form, the causal variables, and the values of the parameters attached to them.

The game starts with the observation that even if a market participant believes that an economist's overarching model adequately represents how outcomes unfold over time, she also understands that it is the aggregate of others' decisions that will determine the price. Because she cannot be sure about others' beliefs, she may think that it is not in her interest to forecast according to an economist's REH model. In deciding whether to do so, she begins a mental eductive process by attempting to guess other participants' price forecasts. She assumes that everyone knows the demand-and-supply specification of the economist's model: "All objective characteristics of the situations (cost function, demand function, and individual payoffs) are assumed to be public information" (Guesnerie 2005: 8).

In this game, participants understand that if their initial guesses differ in the aggregate from the REH forecast, their decisions will result in a market price that differs from the price forecasts that individuals attributed to others. This leads them to contemplate revising their guesses before they make any actual trading decision. Guesnerie examines whether this a priori process might be eductively stable-that is, every market participant comes to the conclusion that she should forecast according to an economist's REH model. He finds that there are parameter values for which the eductive game converges to uniformity among participants' forecasting strategies, just as standard REH models assume. ${ }^{3}$

3. Guesnerie points out that the question of whether REH models with multiple equilibria are eductively stable involves additional considerations. 
In drawing implications for developing alternatives to the $\mathrm{REH}$ approach, Guesnerie (Chapter 1: 62) argues that if an economist's model is eductively stable, "the rational expectations equilibrium coordination is a priori robust ... [and] the eductive approach ... provides the basis [for replacing REE with] . . . the set of rationalizable equilibria." "He then suggests that representations of outcomes in such equilibria provide an alternative view of plausible economic outcomes.

Guesnerie recognizes the problematic nature of the assumption that an economist's model adequately represents each and every market participant's forecasting strategy. However, he argues that "eductive learning may be justified as a kind of shortcut to evolutive learning" (Chapter 1: 56) an adaptive learning and forecasting algorithm that takes into account the co-evolution (two-way interdependence) between participants' forecasting and the model's aggregate outcomes. The connection between eductive and evolutive learning leads from Guesnerie's analysis of REE expectational coordination to the adaptive learning models that George Evans and Seppo Honkapohja present in Chapter 2.

Expectations as Algorithmic Learning

The learning approach recognizes that market participants do not have complete knowledge of the causal process driving outcomes while maintaining the core assumption of contemporary economic analysis. It thus represents participants' learning with mechanical rules.

The adaptive learning models on which Evans and Honkapohja focus in Chapter 2 have emerged as one of the main approaches for portraying participants' expectations when participants are assumed to have incomplete knowledge of an economist's model. These models are based on least squares (LS) regressions. ${ }^{5}$ They represent learning about the process driving a payoff-relevant outcome, such as the market price, with so-called adaptive rules that entail regressing price on a set of causal variables. This regression is reestimated at each point in time as the economist's model generates new prices. The predictions implied by these regressions are used to represent the unfolding of participants' expectations over time.

In contemplating how to justify reliance on LS regressions to portray learning, Evans and Honkapohja (Chapter 2: 101) propose what they call "the 'cognitive consistency principle': economic agents should be assumed to be about as smart as (good) economists." Noting that economists use econometric techniques to learn about the causal process driving outcomes,

4. The eductive-stability approach builds on attempts by game theorists to "rationalize" Nash equilibria (which are equivalent to standard REE in macroeconomics) by appealing to an a priori mental process. For seminal papers, see Bernheim (1984) and Pearce (1984).

5. Chapter 2 contains an extensive list of references concerning the development of econometric learning and various applications. 
Evans and Honkapohja argue that the cognitive consistency principle rationalizes the use of such techniques in modeling participants' expectations.

The early motivation for choosing LS regressions as the basis for econometric learning models, given that many other techniques were available, was to "obtain an understanding of how agents might come to have rational expectations" (Chapter 2: 73). ${ }^{6}$ This early literature assumed that "agents have a correctly specified model with unknown parameters" (Branch and Evans 2003: 2): each market participant knows the "correct" set of causal variables and functional forms, which are assumed to be those chosen by an economist in constructing his model. But they do not know the specific parameter values that they should attach to these variables. They attempt to "learn" these values by running LS regressions.

Learning models based on LS regressions have been used to provide "a test of the plausibility of rational expectations in a particular model" (Chapter 2: 73). Rational expectations were considered plausible if the LS algorithm converged on REE. ${ }^{7}$ Evans and Honkapohja show that whether a model does so depends on the parameter representing the impact of participants' expectations on market outcomes.

In proposing the cognitive consistency principle to justify adaptive learning algorithms, Evans and Honkapohja are aware of Lucas's argument that in the context of their model, non-REH representations of forecasting point to irrationality on the part of market participants. They emphasize that REE is "the natural benchmark" (Chapter 2: 70) for LS learning rules, and they refer to participants' use of such rules as "only boundedly rational in that [participants'] forecasts have systematic forecast errors during the learning process" (Chapter 2: 73).

According to Lucas's story, however, even if LS learning does eventually converge, models that generate forecast errors are the "wrong theory" of transition to REE: such errors would thus lead profit-seeking participants to abandon the LS learning rule attributed to them. ${ }^{8}$ But Evans and Honkapohja argue that these errors are too subtle to be detectable, and that if LS rules converge on REE, they "vanish asymptotically." They conclude that the convergence of a "correctly specified" LS learning rule would provide "a rational foundation for rational expectations" (Chapter 2: 73).

As the econometric adaptive learning approach developed, researchers began to consider learning on the basis of "incorrectly" specified models. They examined models in which participants run regressions on the basis of

6. For a seminal formulation of how LS “learning” can rationalize REH, see Bray (1982) and Evans (1983).

7. LS learning algorithms have also been used as a criterion for selecting the most "plausible" equilibrium in models with multiple equilibria.

8. Frydman (1982) builds on this argument in his critique of efforts to rationalize REH with LS learning rules. 
a restricted set of causal variables or have heterogeneous expectations based on several LS-related learning rules. In Chapter 2, Evans and Honkapohja present macroeconomic applications of such learning models. They focus on what they call "persistent learning dynamics" in which there is not full convergence to REE. Though the limit of the learning process may be close to REE constantly or occasionally, or very far from REE, Evans and Honkapohja argue that such learning dynamics may be consistent with bounded rationality on the part of market participants.

This interpretation of adaptive learning rules that do not converge on REE differs from Guesnerie's interpretation of models in which the eductive game fails to converge. Guesnerie (Chapter 1:51) focuses on important examples of macroeconomic and finance models in which REE is not eductively stable: "the failure of economic theory stressed here concerns expectational coordination." He points out that these cases are, in general, characterized by the absence of stationarity in the data and suggests that we may need to reconsider the "philosophical determinism that has shaped the development of ... economics as a social science" (Chapter 1: 64). Guesnerie concludes that "to be more relevant, our knowledge claims might have to become more modest."

This conclusion, with its concern about the soundness of contemporary models' philosophical underpinnings, sets the stage for the more radical departures from REH that are presented by Sheila Dow in Chapter 3 and by Roman Frydman and Michael Goldberg in Chapter 4. But, before we discuss these contributions, we briefly sketch how the emergence of behavioral finance, despite its reliance on fully predetermined models, helped to pave the way for an alternative approach that jettisons the search for such accounts of change.

\section{Incorporating Psychological and Social Factors} into Behavioral Finance Models

The learning approach attributes to each individual a learning rule that is based on observable time-series data. It supposes that available data and computation (e.g., LS estimation) alone can adequately represent market participants' forecasting strategies, thereby disregarding evidence that psychological and social factors play an important role in how market participants forecast outcomes and make decisions. In contrast, behavioral theorists have incorporated such factors into their macroeconomic and finance models. 9 Although they emphasize "realism" as the hallmark of their approach, behavioral theorists nonetheless believe that REH models

9. Seminal behavioral models include Frankel and Froot (1987) and DeLong et al. (1990). For more recent examples, see Shleifer (2000), Abreu and Brunnermaier (2003), De Grauwe and Grimaldi (2006), and references therein. 
represent how rational participants should forecast the future. Consequently, they have described the departures from REH that they have observed in real-world markets as a symptom of participants' "irrationality" or "bounded rationality."

Nevertheless, because they base their portrayals of expectations on context-specific empirical evidence, behavioral models represent a significant advance over REH's reliance on a priori, supposedly universal, constraints on how market participants should behave. ${ }^{10}$

Of course, behavioral economists' use of mechanical models to formalize their empirical findings means that their representations of forecasting behavior are associated with systematic, easily detectable forecast errors. That, according to Lucas's REH narrative, makes these models "the wrong theory" of longer term regularities in the movements of aggregate variables over time.

To be sure, Lucas did not deny that an inconsistent overarching model might adequately represent the relationship between the causal variables and aggregate outcomes in a certain historical period-all that was needed was insightful selection of the causal variables and a stretch of time that did not involve much change. Indeed, in his widely cited critique of policy analysis based on non-REH models, Lucas (1976) acknowledged the good short-term forecasting performance of the so-called Keynesian econometric models that were developed in the 1960s. But he argued that "'the long-run' implications of ... [these] models are without content" (Lucas 1976: 24).

The reason for this striking claim is rooted in his account of REH: as time passes, market participants would begin to see their forecasting errors and would thus alter the non-REH forecasting rules attributed to them by a behavioral economist. Such revisions of forecasting strategies would render the structure of the behavioral model inadequate as a representation of both individual decisionmaking and market outcomes over the longer term.

\section{Recognizing the Limits of Economists' Knowledge}

Once an economist embraces the core assumption that overarching accounts of change are within his reach, he must choose between two types of models: consistent REH models that, by design, rule out an active role for participants' expectations in driving outcomes, and inconsistent behavioral models that allow for such a role. But this dualism is problematic. On one hand, the fundamental considerations- the causal factors in an economist's model-

10. Behavioral models' explicit appeal to actual empirical findings also contrasts with the cognitive consistency principle's claim that economists' use of econometrics rationalizes basing representations of learning solely on econometric procedures. Leaving aside the observation that econometric methods are only one of many ways in which economists attempt to learn about the world, the principle provides no guidance to economists in selecting a particular econometric procedure, such as LS regression. 
on which REH models focus are likely to be important for understanding outcomes on the individual and aggregate levels. On the other hand, the psychological and social factors that underpin non-REH behavioral representations are clearly relevant for modeling individual decisionmaking and its implications for outcomes in many markets.

In discussing John Maynard Keynes's approach to understanding individual decisionmaking, Dow argues in Chapter 3 that this duality disappears once we acknowledge the inherent imperfection of knowledge on the part of both market participants and economists. Building on Keynes's (1921) critique of the standard (so-called frequentist) approach to quantifying uncertainty, she points to nonroutine change as the primary source of contemporary models' epistemological flaws and empirical failures:

If the system's internal structure is evolving in a nondeterministic manner, and the influences to which it is subject in the future are not known (or are not fully knowable) in advance, then there is no scope for using frequency distributions to quantify a probabilistic or stochastic expectation. [Chapter 3: 114, emphasis added]

This acknowledgment of the limits of economists' and market participants' knowledge implies that fundamental considerations and computations based on them cannot by themselves account for how participants make decisions. Individual decisionmaking is also influenced by social and psychological factors. As Dow emphasizes,

Individuality or agency allows for individual choice as to whether to follow social convention. But sociality means that social-conventional judgment provides the norm, such that expectations are formed interdependently with expectations in the market. This nondeterministic social interactionism is a key ingredient of Keynes's . . . view of the economic system. [Chapter 3: 117, emphasis added]

Discussing how the "framework of social conventions and institutions ... supports decisionmaking under uncertainty" (Chapter 3: 118), Dow argues that the dualism between rationality and irrationality/emotion, which is a hallmark of the contemporary approach to modeling individual behavior, disappears once we acknowledge the limits of our knowledge. She points out that Keynes came to think that human behavior arises from the combination of reason and emotion-that they are complementary rather than contradictory. ${ }^{11}$ "What is rational for agents therefore is not separable from what is emotional" (Chapter 3: 121). 
Dow's critique of the a priori notion of rationality as an artifact of what Guesnerie calls "philosophical determinism" raises a key question: How can economists represent individual decisionmaking in a way that incorporates both fundamental and psychological or social factors without presuming that individuals forgo obvious profit opportunities? Building on Keynes, Dow (Chapter 3: 122) sets out what any answer must assume: "An open system is not the opposite of a closed system, because there is a range of possibilities for openness, depending on which conditions are not met and to what degree. . . . Deviating from a closed system . . . does not mean abandoning theory or formal models."

\section{Moving beyond Fully Predetermined Models of Expectations}

How can economic analysis jettison mechanical representations, and thereby be opened to nonroutine change and imperfect knowledge, while continuing to portray individual and aggregate behavior in mathematical terms? How would this conceptual shift enable economists to accord market participants' expectations an autonomous role and yet avoid presuming that they forgo profit opportunities systematically?

Imperfect Knowledge Economics (IKE), which Frydman and Goldberg introduce in Chapter 4, proposes answers to these essential questions. In modeling market participants' expectations, IKE enables economists to incorporate both fundamental considerations, on which REH theorists focus, and the psychological and social considerations that behavioral economists emphasize. Moreover, despite their recognition of market participants' and economists' ever-imperfect knowledge about the process driving change, IKE macroeconomic and finance models generate empirically testable implications.

IKE stakes out an intermediate position between unrestricted open models, which have no empirical content, and contemporary models, which are based on the premise that change and its consequences can be adequately prespecified with mechanical rules. As in overarching models, the key set of assumptions that impute empirical content to IKE models are those that restrict change. Although IKE stops short of fully prespecifying change, it recognizes that economic behavior must display some regularity if formal economic theory is to generate empirically testable implications. Thus, IKE explores the possibility that individuals' decisionmaking, particularly how they revise their forecasting strategies, exhibits qualitative, contextdependent regularities.

In searching for such regularities to replace REH's a priori constraints, IKE relies in part on findings by behavioral economists and other social scientists concerning individual behavior. Like behavioral finance theorists, Frydman and Goldberg cite the empirical relevance of such evidence to justify its use in modeling participants' expectations. However, unlike the 
behavioral finance approach, IKE formalizes these empirical regularities with qualitative conditions. Moreover, Frydman and Goldberg argue that, in general, one should not expect even qualitative regularities on the individual level to persist indefinitely. That is, they become manifest-or cease to be relevant-at moments that no one can fully predict. Consequently, the conditions that underpin an IKE model's microfoundations-and thus the aggregate outcomes that it implies-are not only qualitative and context dependent but are also contingent.

By acknowledging economists' and market participants' imperfect knowledge, the microfoundations of IKE models abandon the dualism between reason and emotion that divides "rationality" from "irrationality" in contemporary models. As Keynes put it:

We are merely reminding ourselves that human decisions affecting the future, whether personal or political or economic, cannot depend on strict mathematical expectation, since the basis for making such calculations does not exist; and ... that our rational selves [are] choosing between alternatives as best as we are able, calculating where we can, but often falling back for our motive on whim or sentiment or chance. [Keynes 1936: 162, emphasis added]

For Keynes, unlike for behavioral economists, reliance on psychological factors in decisionmaking is not a symptom of irrationality. Rational individuals in the real world use knowledge of facts; but because knowledge is imperfect, calculation alone is insufficient for decisionmaking.

Although Keynes (1936: 162) emphasizes that psychological considerations, such as confidence, play an important role in individual decisionmaking, "we should not conclude from this that everything depends on waves of irrational psychology." Likewise, Frydman and Goldberg argue that psychological considerations themselves could not sustain the recurrent long swings that we observe in asset prices. Indeed, comprehending changes in fundamental factors is crucial for understanding how confidence and other sentiments are influenced over time. ${ }^{12}$

There is a more extreme view, which many economists and nonacademic commentators associate with Knight (1921), that uncertainty is so radical as to preclude economists from saying anything useful about how market outcomes unfold over time. Thus, the evidence that psychology alone cannot drive asset price movements is good news for the possibility of empirically relevant formal economic theory. After all, fundamental considerations are, for the most part, the only tangible factors that economists can use to 
develop models that might enable them to distinguish between alternative explanations of outcomes.

Departing from the positions of Knight and Keynes, Frydman and Goldberg make nonstandard use of probabilistic formalism: they represent outcomes at every point in time with myriad probability distributions. ${ }^{13}$ The qualitative and contingent conditions on which IKE models rely place restrictions on how the conditional moments of these distributions unfold over time-restrictions that are sufficient to generate empirically testable implications for aggregate outcomes.

In Chapter 6, Frydman and Goldberg show how such probabilistic formalism can be used to model market participants' revisions of autonomous forecasting strategies and the fundamental and psychological factors that underlie them. They then examine the implications of such revisions and find that trends in fundamentals play a central role in driving asset price swings away from and back toward benchmark values. In this sense, an IKE model of such swings differs from its behavioral finance counterparts, which imply that swings away from benchmark values are largely driven by nonfundamental factors. Blake LeBaron explores the implications of such a model in Chapter 5.

\section{Part Two: Autonomous Expectations in Long Swings in Asset Prices}

Instability is an inherent feature of capitalist economies, perhaps nowhere more markedly than in modern financial markets. Asset prices and risk tend to undergo long swings around commonly used benchmark values-for example, the price-dividend $(\mathrm{P} / \mathrm{D})$ ratio in equity markets or purchasing power parity values in currency markets-which can persist for years. $\mathrm{REH}$ theorists have encountered much difficulty in accounting for such fluctuations.

In REH models, market participants' expectations are tightly connected to the benchmark, which precludes the possibility that their forecasts might actively push the asset price away from benchmark values. Consequently, although these models can rationalize a slow-moving benchmark, they cannot account for the pronounced persistence that characterizes swings away from and back toward such values. ${ }^{14}$ This failure suggests that according par-

13. For a mathematical exposition, see Frydman and Goldberg (2007) and Chapter 6 of this volume.

14. Frydman et al. (2011) find that currency fluctuations are even more persistent-and thus that REH models' inability to explain them is even more pronounced-than the literature suggests. 
ticipants' expectations an autonomous role in driving outcomes-the role that they actually play in real-world settings-is essential to understanding aggregate outcomes.

\section{Divorcing Asset Price Swings from Fundamentals}

Agent-based computational economics (ACE) has become an influential way to model an active role for expectations in asset markets and individual decisionmaking more broadly. ${ }^{15}$

In Chapter 5, LeBaron develops an ACE model of price swings in the equity market. The model supposes that there are two assets: a "safe" asset that pays a fixed rate of return each period and a risky asset (equity) whose one-period return depends on the market price in the next period, $t+1$, and a dividend that is paid at the beginning of the next period.

The market for the risky asset consists of many participants, each allocating their wealth across the two assets according to a standard mean-variance optimization rule. In making their portfolio decisions, participants are assumed to rely on one of four types of forecasting rules, which are either time invariant or subject to parameter updates using recursive least-squares algorithms.

Two of the forecasting rules play a particularly important role in the model's ability to generate equity-price swings away from the constant P/D ratio that REH would imply. ${ }^{16}$ One is a standard adaptive-expectations rule that assumes that participants revise their one-period-ahead forecast of the mean rate of return on equity by a fixed proportion of their one-period forecasting error. The proportion is a critical parameter in the model, for it determines the weight that participants put on the recent return when forming their expectations, which plays a role in producing persistence in the model.

The other forecasting rule is a "fundamentalist strategy" that relates the forecast of the next period's return to the 52-week average return and the difference between the P/D ratio's value in the current period and its longer run (52-week) average. The fundamentalist strategy always predicts the P/D ratio's reversion in the coming period toward its constant REH benchmark value.

Two factors in the model are important in determining how the equity price unfolds over time: revisions of forecasting rules, ${ }^{17}$ which may include switching from one rule to another, and reallocation of wealth

15. For a broad overview of ACE modeling, see Borrill and Tesfatsion (2011).

16. The dividend process is assumed to follow a random walk with drift.

17. The adaptive forecast involves only fixed forecast parameters, so its updates are trivial, requiring only the most recent return. However, the forecasts generated by other rules are updated in each period using recursive least squares. 
across forecasting rules. This reallocation plays a key role in sustaining a price swing, which is triggered by a shock to the dividend process, by determining whether the aggregate wealth-weighted forecast of return moves persistently away from the benchmark P/D value or reverts relatively quickly to it.

For example, a positive shock to dividends will lead current users of the adaptive rule to bet on the continuation of the incipient trend by allocating a greater proportion of their wealth to equities, which will push the $\mathrm{P} / \mathrm{D}$ ratio away from the benchmark. However, unless additional participants switch to the adaptive rule, the effect of the initial dividend shock on the movement of the P/D ratio will fizzle out. As time passes, the magnitude of upward forecast adjustments implied by the adaptive rule diminishes, thereby reducing participants' desire to bet additional wealth on further increases in the P/D ratio above its longer run average.

LeBaron simulates the evolution of forecasting rules, wealth shares, and equity prices. Each simulation is based on a particular set of parameters, forecasting rules, and their revisions. His simulations generate a rich variety of patterns, some of which mimic the long-swings pattern that one observes in the $\mathrm{P} / \mathrm{D}$ ratio for the S\&P 500 price index.

As LeBaron acknowledges, it remains entirely unclear how well his simulated series match the P/D ratio's characteristics (such as persistence) in real-world equity markets. He cautions that "this series [simulated P/D ratio] is not easy to characterize, and it is possible that visual analysis may be the best that can be done" (Chapter 5: 183-184).

Nevertheless, LeBaron's framework sheds light on the mechanisms underlying the simulated patterns. He traces the simulated pattern of persistent price swings to the set of parameters that drive the reallocation of wealth toward adaptive-expectations strategies: "Throughout the simulation the adaptive types control nearly $30 \%$ of wealth, compared with $15 \%$ for the fundamental types" (Chapter 5: 190). His results indicate that price swings away from the REH benchmark occur because market participants' forecasting strategies increasingly abandon fundamental factors in favor of extrapolating past trends.

LeBaron's account of equity prices is part of a large class of behavioral finance models, a hallmark of which is that long swings away from benchmark values are largely unrelated to fundamental considerations. Some of these models rely on "technical trading" rules, which, like LeBaron's adaptive rule, extrapolate past price trends, while others assume that purely psychological factors can sustain the swing.

To be sure, technical trading and psychological factors play a role in asset price movements. But, again, as Keynes argued, "we should not conclude from this that everything depends on waves of irrational psychology" (Keynes 1936: 162-163). 


\section{Returning Economic Fundamentals to Models of Expectations}

Behavioral finance theorists have assumed that REH is the way to represent how rational participants understand the effect of fundamental factors on asset prices. This has led them to seek accounts of price swings that make "less than full rationality" and nonfundamental considerations the primary factors driving market participants' expectations of payoff-relevant outcomes.

But, as Goldberg and Frydman point out in Chapter 6, models that attribute asset price movements largely to nonfundamental factors are inconsistent with the growing empirical evidence that such variables as interest rates and income growth are the main drivers of fluctuations in currency, equity, and other asset markets. ${ }^{18}$ At the same time, the composition of the relevant set of fundamental factors changes over time in ways that no one can foresee. This suggests that we should not expect that an overarching model would adequately characterize, in terms of fundamental factors, how expectations and asset prices unfold over time.

IKE models of asset markets rest on a core premise: market participants and economists have ever-imperfect knowledge of the relationship between assets' actual prospects- the values of their future earnings and the probabilities with which these values might be realized—and fundamental factors. It is this premise that enables IKE models to incorporate psychological considerations, and yet, in contrast to most behavioral finance models, still accord to fundamental factors the primary role in explaining the persistence of long swings in asset prices and risk. Paradoxically, by abandoning the REH-motivated search for fully predetermined relationships between asset prices and fundamental factors-that is, by conceiving of expectations as being autonomous-IKE can accord such factors a central role in its models of expectations.

In formulating the foundations of their model of asset price swings in Chapter 6, Frydman and Goldberg point out that no a priori universal standard can adequately characterize (as REH purports to do) how rational participants would forecast the future in all contexts and time periods. To model individual decisionmaking, therefore, economists must draw on empirical findings from psychology and other social sciences. They may also use their understanding of the historical record, social norms, conventions, and institutions.

18. Goldberg and Frydman (1996a,b) find that short-term currency fluctuations depend on fundamentals, but that this relationship is temporally unstable. See also Rogoff and Stavrakeva (2008). For evidence that fundamental considerations are the main drivers of equity prices, but in temporally unstable ways, see Mangee (2011). 
In this sense, IKE reframes the relationship between the individual and aggregate levels of analysis: its models' microfoundations incorporate the influence that the broader social and historical context, together with actual aggregate outcomes, has on market participants' decisionmaking process. Even if market participants are purely self-interested, how they deploy their resources depends as much on such social factors as it does on their individual motivations. ${ }^{19}$ Chapter 6 shows how this feature of capitalist economies can be represented in the context of modeling swings in prices and risk in equity markets.

As in LeBaron's model, Frydman and Goldberg assume that the market consists of many participants who hold their wealth in either a risky asset (equity shares) or a safe asset. An IKE model, like standard REH models, represents a participant's forecasting strategy by relating her forecast of a stock's future price and riskiness to a set of fundamental factors. However, in contrast to extant models, an IKE model assumes that market participants revise their forecasting strategies at times and in ways that they themselves, let alone an economist, cannot fully foresee. ${ }^{20}$ Consequently, IKE models stop short of fully prespecifying participants' forecasts at each point in time, as well as their revisions over time. Instead, such models represent forecasting behavior by relying on empirically based conditions that formalize qualitative and contingent regularities.

In Chapter 6, Frydman and Goldberg formalize one such qualitative behavioral observation: regardless of whether participants in financial markets are bulls or bears, they tend to assume that the "existing state of affairs will continue indefinitely, except in so far as [they] have specific reasons to expect a change" (Keynes 1936: 152). ${ }^{21}$ Even when a market participant does "have specific reasons to expect a change," it is entirely unclear which new forecasting strategy, if any, she should adopt. Faced with this uncertainty, participants tend to revise their thinking about how fundamentals matter in what one of us has called "guardedly moderate ways": there are stretches of time during which they either maintain their current strategies or revise them gradually.

But, like price swings themselves, the tendency toward guardedly moderate revisions is not only qualitative but is also contingent. A participant's

19. In this way, IKE's approach to microfoundations of aggregate models contrasts sharply with REH's reliance on methodological individualism.

20. The IKE model in Chapter 6 also differs from extant models in relying on a new specification of preferences, which Frydman and Goldberg call "endogenous prospect theory." This approach adapts the prospect theory of Kahneman and Tversky (1979) to conditions of imperfect knowledge.

21. This regularity is also related to behavioral economists' observation that individuals tend to revise their assessments of probabilities in a way that is much more conservative than the standard Bayesian updating formulas would suggest. See Shleifer (2000). 
decision to revise her forecasting strategy depends on many considerations, including her current strategy's performance, whether she has "specific reasons to expect a change" in fundamental trends or how they are influencing prices, and the "confidence with which we ... forecast" (Keynes 1936: 148). Moreover, using data from media coverage of financial markets, Frydman and Goldberg argue that psychological factors like confidence are partly related to movements in fundamental factors. For example, the exuberance that appeared to sustain the equity price boom of the 1990s quickly evaporated when positive trends in earnings and other fundamental factors began to reverse at the end of that decade.

Frydman and Goldberg show that a price swing arises during periods in which market participants on the whole revise their forecasting strategies in guardedly moderate ways and fundamentals trend in unchanging directions. By relating asset price swings to fundamental factors, an IKE model can be tested on the basis of time-series evidence using econometric procedures. ${ }^{22}$

\section{Part Three: Rethinking Unemployment-Inflation Trade-offs and the Natural Rate Theory}

As different as they are on both theoretical and empirical grounds, the foregoing models of asset price movements bring us back to the Phelps volume's central message: ascribing an autonomous role to market participants' expectations substantially alters our understanding of the processes driving aggregate outcomes. Indeed, a common theme running through the papers presented at the 1969 conference was that the then-prevailing view of monetary policy ignored the role of participants' expectations, and that the belief that expansionary policy could permanently lower unemployment by spurring higher inflation was misguided. Monetary expansion could lower the unemployment rate in the short run, but its effects fizzle out over time: in the long run, nonmonetary factors determine unemployment.

The embrace of REH in the early 1970s led to revisions of these conclusions, particularly concerning the short-run effectiveness of monetary policy. But, as the chapters in Part Three argue, standard REH models obfuscated comprehension of the dynamics of unemployment and thus how changes in monetary policy might affect these dynamics in both the short and long run.

The arguments developed in this part of the volume grapple with the problem of unemployment by exploring alternative approaches to modeling the role of participants' expectations in driving outcomes. As in Parts One 
and Two, some of the authors move beyond REH and fully predetermined models. This leads them to rethink the natural rate theory and how it has been tested empirically. Indeed, the empirical results that they report raise important questions about the dualism between the short-run (cyclical) and long-run (steady state) movements of real output and unemployment-a distinction that plays a key role in contemporary macroeconomic analysis.

\section{From the 1969 Conference to New Keynesian Models}

Friedman (1968) and Phelps (1968, 1970) argued that Phillips's (1958) claim of a permanent trade-off between inflation and unemployment was flawed, because market participants would revise their inflation expectations as the actual inflation rate increased in the wake of expansionary monetary policy. This would render the Phillips curve unstable over time. As Phelps put it in the introduction to the 1969 conference volume:

The crucial role that the new theory assigns to expectations ... of wage and price change, together with the notion of adaptive expectations, ha[s] led most of the authors here to the hypothesis that the momentary Phillips curve will shift according to the point chosen on it. Today's Phillips curve may be quite stable, but tomorrow's curve will depend upon how the economy behaves today. In particular, it may be that an increase in the steady rate of inflation will have only a vanishing effect on the unemployment rate. [Phelps et al. 1970: 4]

In the models in the Phelps volume, the unstable short-run trade-off between inflation and unemployment, together with the long-run "vanishing" of this trade-off, is deduced from an economic system characterized by adaptive expectations. This forecasting rule assumes that for some time-the short run-market participants' assessments of inflation lag behind the actual economywide inflation rate. In the long run, the adaptive rule leads participants' expectations to catch up with the actual inflation rate, while unemployment converges to its natural rate.

Replacing adaptive with "rational" expectations, REH models retained the Phelps volume's conclusion that monetary policy has no effect on the natural rate of unemployment. However, reliance on REH dramatically altered the conclusion concerning inflation-unemployment trade-offs in the short run. As Sargent and Wallace (1975) argued in the context of an REH model, as long as changes in monetary policy are publicly announced, expansionary policy that permanently raises the inflation rate would not be effective in lowering unemployment in either the short or the long run (Sargent and Wallace 1975). Their so-called policy ineffectiveness proposition implied that the only changes in monetary policy that affect unemployment in the short run arise from either purely random shocks or policy- 
makers' attempts to fool the public by not openly announcing changes in monetary policy. As such, monetary policy's effect on unemployment is ephemeral.

To persuade the broader public that such REH-based models should inform public policy, their proponents have invoked Abraham Lincoln's famous adage: the policymaker "can fool all the people some of the time, and some of the people all the time, but [he] cannot fool all the people all the time." But that bit of common sense is inapplicable in this context, because the policy ineffectiveness proposition is an artifact of $\mathrm{REH}$ and thus shares its epistemological flaws and poor empirical track record. ${ }^{23}$

Indeed, as Milton Friedman (1960: 87) pointed out, contrary to the ineffectiveness proposition's claim that a permanent increase in the rate of monetary growth would raise the actual and expected inflation rate with little delay, "there is much evidence that monetary changes have their effect only after a considerable lag and over a long period, and that the lag is rather variable." That lag implies that a policy-induced increase in the monetary growth rate, though unpredictable in terms of the timing and magnitude of its impact, would lead to a lower unemployment rate in the short run. ${ }^{24}$

Despite Friedman's findings of long and variable lags, which called into question the mechanical link between inflation and unemployment implied by fully predetermined models, economists' subsequent embrace of REH solidified their adherence to such models. To maintain REH while attempting to account for the short-run effects of monetary policy on unemployment, macroeconomists had to freight their models with additional constraintsso-called frictions that would prevent wages and prices from rising in lockstep with monetary expansion.

Phelps and Taylor (1977) and Fischer (1977) pointed out that the existence of various contractual arrangements in the economy, such as staggered wage agreements, would preclude a nearly synchronous effect of expansionary monetary policy on actual and expected inflation. They formalized "wage stickiness" in an REH model and concluded that monetary policy had a short-run effect on unemployment. In the long run, unemployment converged to its natural rate.

23. Nevertheless, reliance on such rhetoric has turned out to be remarkably successful in persuading the public that REH-based models' implications, such as the policy ineffectiveness proposition, are relevant for understanding the consequences of monetary policy. For a recent example of the use of the Lincoln adage quoted here, in a popular discussion of REH models, see Sargent (2008).

24. Phelps's (1969) so-called island model rationalized the lagged effect of monetary policy on the inflation rate by appealing to heterogeneous information on the part of each wage- or price-setting firm concerning its competitors' price responses to monetary expansion and the resulting changes in nominal demand. 
Over the past four decades, formalizations of the short-run Phillips curve using various representations of wage and price stickiness have been developed extensively, becoming the cornerstone of the New Keynesian macroeconomic models. ${ }^{25}$ Beyond their use in academic research, these models serve as the core of the dynamic stochastic general equilibrium models that underpin central banks' analyses of the consequences of alternative policies. $^{26}$

In Chapter 7, Roger Farmer constructs an REH model of business cycle fluctuations in aggregate outcomes that jettisons the New Keynesian Phillips curve. A key implication of the model that sets it apart from New Keynesian models is that real output does not converge to its natural level in the long run.

\section{Business Cycles without Frictions}

The canonical New Keynesian model consists of three equations. The investment-saving (IS) curve relates the growth rate of real GDP to the real interest rate and a "demand shock." The so-called Taylor rule characterizes how the central bank adjusts the interest rate to deviations of the inflation rate and real output from their steady state values. Finally, the New Keynesian Phillips curve relates the current-period inflation rate to the expected next-period rate and the gap between real output and its natural steady state level, which in turn depends on a "supply shock."

Because the model uses REH to represent participants' expectations, it precludes the possibility that these expectations might autonomously drive aggregate outcomes, such as the inflation rate and real output, away from their steady state values. Thus, to produce business cycle fluctuations around steady state values, New Keynesian models rely on demand and/or supply shocks and at least partly exogenous (often institutional) frictions, which amplify these shocks' purely random and short-lived effects into longerlasting departures of aggregate outcomes from steady state values. As the effects of these frictions wane over time, inflation and real output converge to their REH-implied steady state values.

Farmer (Chapter 7:256) argues that "price stickiness at the micro level is not large enough for the New Keynesian model to explain the aggregate data." Empirical evidence shows that, though sticky, wages and prices are not sluggish enough for New Keynesian models to generate the persistence that we observe in actual inflation and real output.

25. For a formulation of price stickiness that has been widely used in New Keynesian models, see Calvo (1983).

26. For a seminal development and extensive overview of New Keynesian models, with particular focus on their use in policy analysis, see Woodford (2003). For a recent survey of such models and further references, see Gali (2008). 
Farmer supposes that this persistence stems from market participants' forecasting behavior. To represent this behavior, he uses REH to portray how market participants forecast nominal GDP. Moreover, he constrains these forecasts to take a particular form: they are based on the belief "that the growth rate of nominal GDP follows a random walk" (Chapter 7:263). Imposing this belief together with REH in effect assumes that nominal GDP growth actually follows a random walk; that is, the level of nominal GDP follows a highly persistent pattern, called an "integrated of order two," or $I(2)$, process. ${ }^{27}$ This specification of nominal GDP replaces the New Keynesian Phillips curve. The rest of the model consists of the other two canonical New Keynesian equations: the IS curve and the Taylor policy rule.

Farmer shows that his model has only two steady state equations to determine the three steady state values for the deviation of real output from trend and the inflation and interest rates. In contrast to its behavior in the New Keynesian model, therefore, the deviation of real output from trend in Farmer's monetary model does not converge to zero: although the central bank "can decide how movements in nominal GDP are divided between movements in real output and inflation,... it cannot stabilize all ... variables at the same time" (Chapter 7:265).

Beyond implying a long-run gap between actual unemployment and its natural rate, Farmer's model differs from the New Keynesian model in its analysis of fiscal policy in combating recessions. He argues that "to explain the data, the New Keynesian model must attribute much of the persistence in the unemployment rate to movements in the natural rate of unemployment" (Chapter 7: 269). Because the New Keynesian model represents movements in the natural rate as being driven by supply shocks, this "is a problem for New Keynesians who favor policy activism" (Chapter 7: 269). In contrast, Farmer's model can rationalize the use of government expenditures or taxes by treating such policies as a mean shift in the IS curve's demand shock. "If fiscal policy is effective, then [the Farmer] model provides support for its use in times of high unemployment to increase aggregate demand" (Chapter 7: 270).

The differences in the implications of the Farmer and New Keynesian models arise from replacing the New Keynesian Phillips curve with the assumption that nominal income follows an $I(2)$ process. With REH, then, market participants' expectations are characterized by this belief. Farmer interprets this key assumption as a representation of Keynes's notion of "animal spirits."

But, as Dow discusses at length in Chapter 3, animal spirits compel profit-seeking market participants to make investment decisions despite "the

27. In Chapter 10, Katarina Juselius provides an extensive discussion of $I(2)$ processes and further references. 
extreme precariousness of the basis of knowledge on which our estimates of prospective yield have to be made" (Keynes 1936: 149). Keynes invoked the notion of animal spirits to characterize situations in which standard probabilistic representations, which underpin REH, cannot adequately capture participants' beliefs concerning future outcomes.

In Chapter 8, Phelps explores how moving away from REH and recognizing the "precariousness of our knowledge" concerning assets' future prospects substantially changes the meaning of the natural rate. He argues "that the term 'natural' is obviously inappropriate once we recognize that the unemployment rate to which the economy tends is contingent on the market's guesses about the future-that is, future prices of capital goods and labor" (Chapter 8: 291).

\section{Moving beyond Fully Predetermined Models of the Natural Rate}

The contributors to the Phelps 1969 conference supposed that the natural rate of unemployment is a constant that corresponds to steady output growth. ${ }^{28}$ Consequently, they modeled the observed swings in real output and unemployment as business cycle fluctuations around their respective steady state values. These fluctuations were thought to be triggered primarily by shocks, real or monetary, that were propagated through monetary channels.

In Structural Slumps (1994), Phelps argued that the comovements of inflation and unemployment during the final four decades of the twentieth century did not seem consistent with these models' implications. Although inflation rates were relatively low and stable, economic activity fluctuated widely. In the 1960s, unemployment nearly vanished in several European countries, without fueling high inflation. Symmetrically, unemployment was high in the 1980s in nearly all OECD economies, but there was little or no disinflation-and even considerable inflation in France and some other economies. Then, in the 1990s, unemployment in several OECD economies fell sharply, with little inflation, or even some disinflation. Such observations led Phelps to develop a theory that attributes swings in unemployment to nonmonetary shocks and developments operating through nonmonetary channels. In Chapter 8, he sketches the key steps in the development of his theory of "structural" booms and slumps.

The early structuralist models in Phelps (1994) have the property that the equilibrium path of unemployment always approaches the natural rate, as do the monetary models in the Phelps et al. (1970) volume and New

28. Phelps did not require the "equilibrium," or "warranted" unemployment rate, in his terminology of that time, to be invariant to real interest rates, real wealth, or, for that matter, real exchange rates. As a result, structural shifts that changed those determinants would alter the "natural" unemployment rate. 
Keynesian models. In Structural Slumps, "something has been added. The natural rate moves!” (Phelps 1994: vii). Moreover, econometric analysis finds that the historical fluctuations in the actual rate arise largely from the structural forces driving the natural rate.

The structuralist approach regards investment-and thus expectations of its profitability and the unanticipated events that raise or lower those expectations-as the key force driving long swings in real output and unemployment. In the models developed by Hoon and Phelps (1992), Phelps (1994), and Phelps and Zoega (1998), firms undertake investment in a business asset (fixed capital, the stock of customers, or job-ready employees). The asset's per-unit valuation has a positive impact on the pace of investment: it boosts construction (which is labor intensive), competition for customers (which shrinks markups), or workers' preparation to be functioning employees. Increased investment, in turn, has a positive impact on labor demand, lowering unemployment and raising wages.

Movements of investment and employment are determined in these models alongside those of the real interest rate, the real exchange rate, and wealth. These movements unfold along a "conditional" equilibrium path that assumes that absent any significant and unforeseeable structural shift, participants have "correct" expectations about assets' prospects, whatever they might be. But, rather than study the movements along the equilibrium path, Phelps and Zoega examine how that path would change when one of the structural parameters shifts. In particular, they examine the consequences of shifts in productivity growth and expectations concerning prospects for profitable new investment opportunities. ${ }^{29}$

According to structuralist models, "the sudden expectation of a future surge of productivity creates an expected simultaneous surge of profits; this at once prompts a speculative lift in the asset valuation, which will look unjustified to uninformed observers; the increased valuation sets in motion an upswing in employment; when the productivity surge is realized, employment subsides." These models claim that "such expectations are potentially important: that an unusually large shift of this sort in the valuation of business assets would cause an unusually wide structural expansion or contraction" (Phelps and Zoega 2001: 3).

Phelps and Zoega emphasize that the shift in valuations is not purely a result of psychological factors, as supposed by Pigou (1927) and by more recent behavioral models. "In this account, the boom is not sparked by the 'optimism' and not doomed by the 'miscalculations'" (Phelps and Zoega

29. The 1994 volume postulated punctuated expectational equilibrium, so that, after an unanticipated structural shift, expectations are corrected. The aim was only to put the focus on how very differently the model behaves from the Keynesian and classical models it bid to replace. 
2001: 3). ${ }^{30}$ In contrast to Pigou's thesis that "the response of investments to a class of future prospects exceeded what 'rational' calculation would suggest ('errors in optimism'), . . . [structuralist theory relied] on the effects of future prospects that it is 'rational' for investments of various kinds to respond to" (Phelps 2006: 69, emphasis added).

In considering how to model "rational" market participants' expectations of assets' future prospects, Phelps (Chapter 8: 285) points out that the structuralist model "is not inherently yoked to perfect knowledge . . . or to [its] offspring, rational expectations . . . the Hoon-Phelps papers of 20022006 on 'structural booms'-handle the arbitrariness in valuations at least as naturally as Keynes's 'marginal efficiency' did."

Opening the way for accounts of unemployment that move beyond REH and fully predetermined models, Phelps (Chapter 8: 285) emphasizes that expectations of assets' prospects, which determine their market valuations, do "not have to be 'solved out' by supposing perfect understanding of the working of the economy-as I was driven to do in Structural Slumps to minimize the complexity of the models and the themes." These expectations-influenced by participants' own understanding of the future, as well as by their autonomous intuitions, instincts, and emotional needs-may be taken as given, much as Keynes did. A downward shift in these expectations leads to a drop in observed valuations, which in turn leads to a shift from one equilibrium unemployment path, with its supposed destination, to another. This approach treats participants' expectations as a structural parameter and thus sidesteps the problem of how market participants settle on particular expectations, and how they might revise them. Nonetheless, it moves beyond REH, which regards expectations as an endogenous factor determined by an economist's own model, because treating expectations as a structural parameter recognizes that they play an autonomous role in driving outcomes. It also recognizes that the future is inherently open, and that how it unfolds depends crucially on participants' revisions of their expectations; thus, these models' predictions are necessarily contingent on how we represent these expectations. ${ }^{31}$

Such considerations lead Phelps (Chapter 8: 291) to the key question: "Does this ... mean that the "natural' level of (un)employment no longer exists?" Phelps recognizes the importance of "radical uncertainty," in the sense of Knight and Keynes: the economy's structure is always changing in ways that cannot be modeled in standard probabilistic terms, and, "with

30. This argument echoes Keynes's view that psychological factors alone cannot sustain asset price swings if fundamental considerations suggest that investment prospects have substantially worsened (Frydman and Goldberg 2011).

31. IKE is based on the same premise. See Chapters 4 and 6 and Frydman et al. (2011) for a discussion of the concept of contingent predictions and how IKE models, despite their openness with respect to forecast revisions, generate empirically testable implications. 
it, the unemployment rate to which the system may-or may not-tend." For Phelps (Chapter 8: 291), "the 'contingent equilibrium' rate would be a better term than 'natural' for that conception of the homing tendency." In his chapter, he works out the valuations that participants place on a unit of capital and on a unit of labor in the present, given their expectations of future productivity levels for each of these factors of production, and given their understanding of how the economy works, an understanding that the analyst's model is assumed to represent.

Phelps then sharply contrasts his position to what has become known as Keynesian macroeconomics:

It is ironic that the originators of models of the natural rate, whose formulations did not explicitly exclude that background expectations of future capital goods prices and future wages might be quite wrong, stand accused of not appreciating that any sort of economic equilibrium is to some extent a social phenomenon-a creature of beliefs, optimism, the policy climate, and so forth-while today's crude Keynesians, despite their mechanical deterministic approach, wrap themselves in the mantle of Keynes, who, with his profound sense of indeterminacy and, consequently, radical uncertainty, was worlds away from their thinking. [Chapter 8: 291]

Phelps and Zoega (2001) argue that, despite this contingency, structuralist models generate an empirically testable implication concerning the shifting relationship between average valuations of assets and the average unemployment level: during stretches of time in which valuations tend to be relatively high (low), the unemployment rate should be relatively low (high). In Chapter 9, Gylfi Zoega presents empirical evidence about this relationship that uses asset prices as a proxy for autonomous expectations concerning their prospects (and thus their valuations).

Unemployment, Share Prices, and Investment

The key premise of the first structuralist models was that actual unemployment primarily reflects movements in the natural rate. This premise implied "that asset valuations belong in the employment growth equation or unemployment equation" (Phelps and Zoega 2001: 20). Hoon and Phelps (1992) and Phelps and Zoega (2001) worked out the dynamics of business assets' shadow price (equivalently, the share price) as they enter a trajectory approaching the expected resting point. If the shadow price is rising to meet this point, the rate of investment in the business asset is rising, too.

In Chapter 9, Zoega examines empirical evidence concerning such a relationship, using share prices in 16 OECD countries from 1960 to 2009 as proxies for market participants' expectations of business assets' prospectstheir future profitability-and their assessments of the current state of real business activity. 
Prior to undertaking an econometric investigation, Zoega examines descriptive evidence concerning six countries with sharply different historical employment rates. Although mean unemployment in three of the countries (Belgium, Italy, and Spain) tended to shift upward throughout the period, in the Netherlands, the United Kingdom, and the United States, unemployment reverted to its earlier mean following recessions.

To capture the observation that hiring decisions do not have an instantaneous effect on the employment level, the share-price variable is set to its average for the first 3 years of each half-decade of the period, whereas the employment rate is set to its average for the last 3 years of each half-decade. Zoega (Chapter 9: 310) observes that a "clear upward-sloping relationship [between the employment rate and share prices] is apparent for each of the countries." Estimates of a pooled cross-section time-series regression for the 16 OECD countries "confirm a robust relationship between share prices and unemployment ... [and thus] suggest . . . that changes in the level of share prices precede changes in the rate of employment" (Chapter 9: 312).

The structuralist view also suggests that business investment is one of the principal factors underlying employment movements. To examine this channel, Zoega, noting that employment and investment are related, replaces share prices with gross capital formation (as a share of GDP) in his employment equation.

Beyond examining bivariate correlations, Zoega explores whether changes in share prices "cause" changes in employment. To this end, he converts the data to annual averages and applies Granger causality tests. The null hypothesis that changes in average share prices do not cause changes in average employment "can be rejected for 14 of the 16 countries. . . . [Moreover,] the alternative hypothesis of changes in employment not . . . causing changes in share prices can only be rejected for two countries" (Chapter 9: 313).

Zoega's empirical methodology reflects the comparative statics approach to analyzing the implications of structuralist models. This approach assumes that, "absent any significant and unforeseeable structural shift," the configuration of the macroeconomic relationships does not change very much, and that structural shifts "are very infrequent" (Phelps and Zoega 2001: 93). The reliance on averages is supposed to capture the unchanging processes driving macroeconomic variables, such as share prices and employment, during the period in which a conditional equilibrium prevails. Each such equilibrium path is supposed to last for only a limited time; it shifts when one of the structural parameters shifts. The regression analysis relating the half-decade averages of, say, employment rates and share prices aims to capture how the average employment rate, moving along an equilibrium path, would change in response to occasional shifts in participants' expectations concerning assets' prospects.

The IKE approach (Chapters 4 and 6) provides a way to model revisions of exogenous expectations of asset prices, which, in Phelps (1999) and en- 
suing studies, underpin shifts in the structuralist equilibrium path. Katarina Juselius pursues this line of research in Chapter 10. In her account, expectations drive the real exchange rate and the real interest rate, which, in turn, are among the key variables underlying unemployment movements in the structuralist model. Juselius confronts the structuralist account of unemployment with empirical evidence by embedding it in the multivariate cointegrated vector autoregressive (CVAR) model (Johansen 1996; Juselius 2006).

Unemployment Fluctuations and Swings in Asset Markets

According to the structuralist theory, three variables-the real exchange rate, the real interest rate, and markups of prices over costs-are the main determinants of the unemployment rate. As these variables tend to undergo protracted swings around their benchmark values, the unemployment rate also undergoes swings. In Chapter 10, Juselius examines whether the theoretical implications of combining the IKE approach to asset price swings with the structuralist model of unemployment are consistent with the empirical evidence. She surveys previous empirical studies concerning comovements among the unemployment rate, the real exchange rate, and the real interest rate, as well as markups of prices over costs (which, according to the structuralist model, is a principal channel through which asset market outcomes are transmitted to the real economy).

These studies share a common econometric framework: the CVAR model. Juselius argues that one of the CVAR model's main advantages over other approaches stems from its ability to represent covariances among "persistent" variables, that is, variables characterized by nonstationary processes, such as random walks in levels or first differences (referred to as $I(1)$ or $I(2)$ models, respectively). Such nonstationarity is typical in macroeconomic time series. The CVAR econometric model summarizes the covariance structure of such nonstationary time series by expressing comovements among the model's variables in terms of cointegrating relationships involving their values, as well as first- and higher order differences.

To confront theoretical representations, such as the structuralist models of unemployment in Phelps (1994), with time-series evidence, Juselius translates their testable implications into a set of hypotheses about the parameters of the CVAR model describing long-run relationships, adjustment dynamics, driving trends, and their effects on the model's variables. ${ }^{32}$ The

32. Juselius contrasts the CVAR approach with extant approaches to testing REH models, which often involve the imposition of restrictions-"the use of mild force to make [the data] tell ... [the] story" (Chapter 10: 346) that is consistent with a particular model. Estimation of contemporary models typically disregards the possibility of structural change. Moreover, in many cases (including REH and behavioral finance models), the "testing" dispenses with statistical analysis altogether, relying instead on calibration and computer simulations. In contrast, the CVAR methodology starts by estimating the data's largely unrestricted covariance structure, including their temporal breaks, and then asks whether the implications of one or more theoretical models are consistent with the estimated statistical model. 
analysis of the CVAR model also generates estimated empirical regularities concerning the comovements of macroeconomic aggregates. In Chapter 10, Juselius discusses several such tests and empirical regularities. In doing so, she draws on the results of previous CVAR-based studies of asset markets, the real economy, and their two-way interdependence.

To set the stage for empirical testing of the structuralist model, Juselius analyzes the persistence of the real exchange and real interest rates in the context of the IKE model elaborated in Chapter 6. She observes that for this model of asset price swings to be useful in testing whether structuralist theories can help account for the fluctuations in the unemployment rate, the IKE model must imply that both real exchange rates and real interest rates are persistent.

Frydman et al. (2012) show that this is the case. Even though its restrictions on individual behavior are qualitative and contingent, the IKE model yields testable implications for time-series data: highly persistent real exchange rate and real interest rate differentials that can be characterized as near $I(2)$. Juselius shows that this characterization is consistent with empirical evidence. ${ }^{33}$

Having examined persistence, Juselius reports empirical evidence suggesting that real exchange rates and real interest rates comove: they tend to undergo parallel swings away from and toward their respective benchmark values. This comovement, which is implied by the IKE model, plays a key role in confronting the implications of Phelps's (1994) theory with time-series data on relevant macroeconomic aggregates.

One of the main implications of the structuralist theory is that real exchange rate appreciation, by lowering the price of competing foreign goods, reduces firms' markups of prices over costs. This implies that the real exchange rate and the economy's profit share, which proxies for an aggregate of markups, comove: profit share would decline (rise) during the periods of persistent appreciation (depreciation) of the real exchange rate. This implication is consistent with the "evidence of a non-stationary profit share co-moving with the real exchange rate" (Juselius 2006: 378-379).

Taken together, the negative comovement of the profit share and the real exchange rate and the positive comovement of the real exchange rate and the real interest rate imply that unemployment would, according to

33. Juselius argues that, beyond providing a summary of the covariance structure of the data that is superior to those provided by other econometric approaches, the multivariate CVAR framework is crucial for uncovering the $I(2)$ persistence displayed by asset prices and other macroeconomic time series. Although the literature has reported results consistent with such persistence (e.g., see Engel and Hamilton 1990), the vast majority of studies, which have relied on univariate procedures, have rejected $I(2)$ in favor of $I(1)$ persistence. Juselius (2012) shows that such tests lack sufficient power to detect the $I(2)$ nonstationarity that arises from the slowly unfolding trends that underlie persistence in asset prices. 
the structuralist model, persistently rise during periods in which the real interest rate undergoes a persistent upswing. Juselius (2006) found that unemployment comoves positively with the real interest rate.

Thus, reliance on the structuralist model to represent the transmission process by which asset markets influence the real economy generates an important implication: given persistent movements in real interest rates, the natural rate of unemployment is nonstationary. Juselius (2006) and Juselius and Ordonez (2009) provide empirical evidence for such a transmission process and, with it, for the nonstationarity of the natural rate.

The empirical analyses of Zoega and Juselius focus on nonmonetary factors that, according to the structuralist theory, influence the natural rate of unemployment. As the natural rate is not observable, they rely on the assumption that swings in the actual unemployment rate largely reflect the movements of the natural rate. However, as Phelps (1994: 314) pointed out, "the data on the actual rate of unemployment in any country unquestionably reflect . . . the influence of monetary [factors]." This opens the possibility that monetary policy, as well as other macroeconomic policies aiming to attenuate cyclical fluctuations in economic activity in the short run, may influence the trend growth of real output and the movement of the long-run "natural" unemployment rate that is associated with such changes. In Chapter 11, Philippe Aghion and Enisse Kharroubi argue that such a connection between short-run stabilization policies and the long-run behavior of real output and unemployment is empirically significant.

\section{Stabilization Policies and Economic Growth}

The conventional wisdom among economists and nonacademic commentators is that there is no connection between short-run macroeconomic policies and an economy's trend growth rate. The findings of Juselius in Chapter 10, which connect fluctuations in currency markets to movements in the natural rate of unemployment, suggest otherwise.

In Chapter 11, Aghion and Kharroubi present further evidence that challenges the conventional view. Their empirical analysis appeals to the argument advanced by Aghion et al. (2008) that growth-enhancing investments (in skills, research and development, or structural capital) need to be maintained over the long run. Business cycle fluctuations, they argue, tend to be detrimental to innovation and growth, particularly for firms facing credit constraints that prevent them from investing more than some multiple of their cash flow. As cash flows decline during recessions, such firms are forced to cut productivity-enhancing investments, thereby contributing to a reduction in the long-run growth rate.

Aghion and Kharroubi therefore argue that active countercyclical stabilization policies "may have [significant] implications for long-term growth. For instance, if monetary policy reduces the cost of short-term refinancing in 
downturns . . . that should help firms go through downturns without having to cut ... [growth-]enhancing investments" (Chapter 11: 352). To test this hypothesis empirically, they compare the size and effects of active fiscal and monetary policies on growth across industries in countries that differ in the degree to which they pursue active stabilization policies.

Using panel regressions based on data from 15 OECD countries, Aghion and Kharroubi examine whether industries that faced tighter financial constraints tended to grow faster in countries with active fiscal and monetary policies. To proxy the degree of financial dependence on external credit markets, they use industry measures of borrowing or liquidity constraints. They estimate the degree of countercyclicality of a country's stabilization policy (fiscal or monetary) according to the sensitivity with which the policy responds to the output gap (departures of real output from its long-run trend).

For fiscal policy, they use two alternative measures of fiscal balance. Because these indicators are available only annually, they estimate their effects on industry growth across countries over a relatively long period, 1980-2005. Their regression results show that "increased sensitivity of fiscal balance . . . to the output gap raises . . . real value added growth disproportionately for industries with [higher financial dependence]" (Chapter 11: 357).

Aghion and Kharroubi also investigate the relationship between industry growth and countercyclicality of monetary policy across countries, using the short-term real interest rate as a proxy for the monetary policy stance. Relying on quarterly observations, the analysis spans 1995-2005. As is true of active fiscal policy, their empirical results show that a degree of countercyclicality of a country's monetary policy "tends to raise ... real value added growth disproportionately for industries with higher financial dependence" (Chapter 11: 362). They conclude that "the effect of countercyclical fiscal or monetary policy is economically significant [in the long run] and cannot be discarded as being of second-order importance" (Chapter 11: 353).

Aghion et al. (2008: 3) emphasize that, "while [such effects] provide some justification for stimulus packages during recessions, this justification is quite distinct from the argument based on Keynesian multipliers.” Although the standard multiplier analysis relies on the short-run demand-side effects of active stabilization policies, the results reported in Aghion and Kharroubi call attention to the way in which such policies affect long-run growth, primarily through the supply side of the economy.

\section{Short-Run (Cyclical) versus Long-Run Unemployment?}

The empirical results obtained by Aghion and Kharroubi point to a connection between cyclical fluctuations in real output and its long-run growth. However, the structuralist approach to unemployment fluctuations does not 
model short-run behavior; its account of unemployment relies on the factors that drive the long-run natural rate.

Indeed, the empirical analyses of the structuralist theory of unemployment, in Phelps (1994), Phelps and Zoega (2001), and Chapters 9 and 10 of this volume, come close to jettisoning altogether the distinction between cyclical movements in unemployment and its long-run behavior. ${ }^{34}$ These studies assume that observed quarterly unemployment fluctuations, which are typically referred to as short-run or cyclical, largely reflect the movements of long-run natural rate unemployment.

As we have discussed, share prices, real interest rates, and real exchange rates tend to undergo persistent upswings and downswings that do not converge or abate. According to structuralist models, therefore, unemployment also tends to fluctuate without settling down in the long run. Indeed, Juselius finds that unemployment follows a persistent $I(2)$ process and that its fluctuations stem largely from persistent swings in the real interest rate and the real exchange rate.

This characterization of the unemployment rate as a highly persistent process accords well with the view of Phelps $(1994,2006)$ and Phelps and Zoega (2001) that market participants' expectations of assets' prospects are among the main drivers of unemployment. The IKE model in Chapter 6 lends further support to this claim by showing that the $I(2)$ trends found in asset prices reflect market participants' (as well as economists') imperfect knowledge (see Frydman et al. 2011).

Beyond raising doubts about the dualism of cyclical and long-run unemployment, the finding of near- $I(2)$ persistence points to fundamental difficulties in using mechanical rules to understand how to conduct monetary and other macroeconomic policies. For example, Taylor rules relate the interest rate to the gap between the current and long-run unemployment rate. But the unemployment rate's persistent character raises fundamental questions concerning the definition and measurement of this gap.

Advocating that macroeconomic policy be conducted according to rules presupposes that its sole role is to offset any "shocks" that buffet the system. Absent such shocks, the economy would be growing at its "normal" steady pace, with unemployment at its natural rate. These representations of the

34. Phelps (1994) includes the inflation rate in the unemployment equation to control for cyclical influences. But he does not model short-run movement, and his account of unemployment relies on the factors that drive the movements of the natural rate. His reliance on expectational shifts to model macroeconomic fluctuations stands in sharp contrast to the so-called real business cycle approach. Because these models rely on REH, they rule out the possibility that participants' expectations play an autonomous role in understanding movements in unemployment; instead, cyclical fluctuations supposedly arise solely from various "shocks" and ad hoc "frictions." For a survey of various attempts to identify these shocks, see Rebelo (2005). For the seminal exposition of the real business cycle approach, see Kydland and Prescott (1982). 
economy underpin the view that policymakers should have virtually no scope for discretion. In Chapter 12, John Taylor discusses how the debate over reliance on rules versus discretion has unfolded over time.

\section{Part Four: Policymaking after "Rational Expectations"}

The finding of nonstationary and highly persistent $I(2)$ unemployment rates suggests that fluctuations, rather than steady output growth, are the "normal" behavior of such macroeconomic aggregates in modern capitalist economies. These economies thrive on nonroutine change, which leads to shifts in the processes driving outcomes, engenders imperfect knowledge about these processes, and thus is among the primary causes of instability.

Friedrich Hayek and Milton Friedman argued that the economic rationale for constraining officials to follow fully predetermined rules stems from inherently imperfect knowledge about how economic policies affect individual behavior and aggregate outcomes over time. In contrast, contemporary arguments for rule-based policymaking appeal to REH, which assumes away imperfect knowledge on the part of policymakers and market participants. In Chapter 12, Taylor documents the profound impact of the REH approach on how economic policy has come to be conducted.

\section{Shifts in the Rules-Discretion Balance}

For Hayek (1978: 34), the claim that state intervention could not improve on outcomes produced by unfettered markets stemmed from his "recognition of the insuperable limits of our knowledge." He pointed out that markets' essential role in allocating society's resources to alternative uses, particularly its savings to diverse investment projects, stems from nonroutine change and imperfect knowledge. This was the essence of his prescient argument that central planning is impossible in principle. ${ }^{35}$

To be sure, policymakers, too, face ever-imperfect knowledge, and active intervention in markets is fraught with difficulty. Echoing Hayek, Friedman (1968) invoked the imperfection of knowledge-the inability to know when and how a discretionary change in monetary policy might affect the economy - to argue that central banks should be constrained by fixed rules. But, as influential as Friedman's empirical findings of "long and variable lags" have been, they lacked a rigorous theoretical underpinning, for the simple reason that prevailing economic theory, then as now, has assumed

35. See Hayek (1948). The inherent tension between contemporary theory's disregard of imperfect knowledge and the appeal to Hayek's arguments in support of markets has again become apparent in debates about public policy in the wake of the global financial crisis. See Cochrane (2009) and Frydman and Goldberg (2011). 
away economists' ever-imperfect knowledge about how alternative policies influence market participants' expectations and aggregate outcomes.

As Taylor points out in Chapter 12, Hayek's arguments for policy rules have primarily appealed to political and normative considerations; for example, that the state, beyond enforcing the rule of law, has no authority to interfere with individuals' freedom to act as they choose. "Stripped of all technicalities, this means that government in all its actions is bound by rules fixed and announced beforehand-rules which make it possible to foresee with fair certainty how the authority will use its coercive powers in given circumstances and to plan one's individual affairs on the basis of this knowledge" (Hayek 1944: 112, emphasis added).

However, such arguments cannot provide an economic rationale for rules. In particular, they cannot support the claim that allowing policymakers discretion would necessarily result in inferior economic performance. REH models were widely seen as providing the missing "scientific" rationale for banning discretion in all circumstances. ${ }^{36}$ As we have noted, early REH-based models assumed that monetary policy could influence unemployment only by fooling market participants, and that, left to themselves, financial markets populated by so-called rational participants would allocate resources nearly perfectly. As Taylor (Chapter 12: 374) notes, "the $[\mathrm{REH}]$ macro policy evaluation by Lucas $(1976)$. . . reinforced the economic rationale for rules.”

Lucas's critique examined the validity of policy analysis based on largescale Keynesian econometric models. These models typically included a number of policy variables, such as interest rates, money supply growth, or tax rates. Policy analysis involved the use of these models' estimates, based on historical data, to simulate the paths of macroeconomic outcomes, such as inflation or unemployment, under alternative trajectories for selected policy variables. Lucas pointed out that "for [Keynesian policy analysis] to have any meaning, it is essential that the structure [of the model] not vary systematically with the choice of the sequence of [a policy variable]" (Lucas 1976: 25).

The main point of Lucas's critique was the untenability of the premise that models with the same structure could adequately represent the causal process driving outcomes both before and after a change in policy. Lucas argued that changes in policy variables would alter the way that market

36. The belief in the scientific status of REH-based conclusions was so strong that leading economists advocated far-reaching institutional changes to eliminate discretion on the part of policymakers. In a seminal paper, for example, Kydland and Prescott (1977: 487) advocate

institutional arrangements which make it difficult and time-consuming to change the policy rules in all but emergency situations. One possible institutional arrangement is for Congress to legislate monetary and fiscal policy rules and these rules to become effective only after a 2-year delay. This would make discretionary policy all but impossible. 
participants forecast the future and hence their decisionmaking. In general, this change on the individual level would also alter the causal process driving aggregate outcomes, thereby rendering policy analysis based on Keynesian models "invalid."

Lucas offered a straightforward solution to this daunting problem: REH would enable policymakers to represent exactly the change in the structure of their models that would result from market participants' revisions of their forecasting strategies following the contemplated change in policy.

Taylor (Chapter 12: 376) acknowledges that "though I and many others have favored rules over discretion for economic reasons, when it comes to explaining shifts in the balance between rules and discretion over time, ... political factors must also be considered." He therefore invokes such considerations to explain the shifts in the rules-discretion balance during the closing decades of the twentieth century. For example, he points out that "there was clearly a political change in the 1980s in the United States and in the United Kingdom in which attitudes favoring more limited government and corresponding encouragement of free markets were on the rise" (Chapter 12: 385).

This shift was maintained—and extended—even after President Bill Clinton and Prime Minister Tony Blair succeeded putatively more conservative governments. Such bipartisan political support for unfettered markets highlights the remarkably broad resonance of the belief that REH-based models' implications for the balance between state and market are based on sound scientific foundations. REH also suggested that policymakers could influence market participants' expectations to a far greater degree than was actually possible, given that policy instruments might work quite differently than expected in real-world markets (in which nonroutine change is an ever-present possibility).

Drawing on Federal Open Market Committee transcripts that contain "a large number of references to policy rules and related developments" (Chapter 12: 377), Taylor documents the profound impact of rules on the conduct and instruments of U.S. monetary policy. For example, in considering how its policies should be communicated to the public, the Federal Reserve has implicitly adopted REH models' premise that imperfect knowledge is unimportant for understanding outcomes. Consequently, policymakers focus on transparency of information and disregard altogether their own, as well as market participants', inherent difficulties in interpreting how changes in economic policy would affect outcomes.

Although REH's flaws imply that its models cannot provide the rationale for rule-based policymaking, this does not necessarily mean that other constraints, such as qualitative guidelines, have no place in thinking about the objectives, design, and implementation of economic policies. What REH's flaws do suggest is that the question of rules versus discretion needs to be reexamined using models that recognize that nonroutine change and imperfect knowledge are essential to understanding the consequences of 
economic policies in real-world markets. The crisis that erupted in 2008 has, if nothing else, made starkly clear the need for such a reexamination.

\section{Rules versus Discretion after "Rational Expectations"}

Echoing Hayek and Friedman, Lucas (1976: 46) asserted that constraining policymakers to follow fully predetermined rules "accord[s] well with a preference for democratic decision-making." However, in sharp contrast to Hayek's and Friedman's appeal to imperfect knowledge, Lucas and his followers have claimed that REH models provide an explicitly economic rationale for rule-based policymaking.

As they do with all their other components, REH models represent economic policies with fully predetermined rules. Consequently, that is how a typical macroeconomist nowadays represents alternative policies. Lucas takes for granted that "the only scientific quantitative policy evaluations available to us are comparisons of the consequences of alternative policy rules" (Lucas 1976: 41, emphasis in the original) in the context of his own REH model. ${ }^{37}$

In Chapter 13, Michael Woodford acknowledges that nonroutine change undermines the desirability of standard REH-based policy rules. However, he emphasizes that

the reconsideration of macroeconomic theory and policy that is necessary in the wake of the global financial crisis . . . does not eliminate the need to assess policy strategies, ... even if such strategies cannot realistically be supposed to represent complete specifications of behavior in all possible circumstances. Nor does it eliminate the potential benefits from requiring policy decisions to be based on general principles, rather than making an ad hoc decision about what will achieve the best outcome under current circumstances. [Chapter 13: 392]

In an attempt to reconcile rules with recognition that nonroutine change may create circumstances in which policymakers must exercise discretion, Woodford proposes to reframe the rules-versus-discretion debate. He observes that "there are different levels at which it is possible to describe the process through which policy decisions are to be made" (Chapter 13: 385). He then argues that "the levels of description differ in the degree to which it is useful to imagine specifying a rule for policy in advance" (Chapter 13: 398).

Woodford discusses how the instruments and conduct of monetary policy could follow from such policy design and implementation. He illustrates his approach, which he calls "principled policymaking," by discussing how the 
specificity and degree of monetary policy's precommitment already depends in some respects on how important nonroutine change is likely to be for the different levels on which policy is implemented.

Specifically, he argues that at the lowest level, where policy decisions pertain to largely routine situations, they could be specified in advance with mechanical rules. For example, such a rule would specify a decision about the quantity of bank reserves to inject or withdraw each day, typically through open-market purchases or repo transactions, as a function of some observable conditions.

Policy decisions on the higher, "instrument" level pertain to largely routine circumstances as well, according to Woodford, and they also can be fully prespecified with a mechanical rule. Such decisions involve, for example, the choice of an operating target for a particular overnight interest rate- the federal funds rate.

Moving to the highest level of description, Woodford considers policy decisions that involve various forms of so-called inflation targeting. For example, "many central banks now have explicit quantitative targets for some measure of medium-run inflation; a few have also been fairly explicit about the criteria used to judge whether near-term economic projections are acceptable" (Chapter 13: 397).

Notwithstanding the central bank's supposedly firm precommitment, Woodford acknowledges that nonroutine change might lead it to revise its pre-announced target. He points out that "one would specify the principles on which policy targets are chosen, given a particular model of the way that monetary policy affects the economy." As a result, "a commitment to specified principles at this level could be maintained in the face of a change in either the structure of the economy or policymakers' understanding of that structure." However, he notes that "it might well be appropriate to modify a central bank's policy targets in light of such change" (Chapter 13: 397)..$^{38}$

It seems to us that the inherent ambiguity about the appropriate response to nonroutine change underscores the key reason policymaking should not be fully rule based: whether and how the central bank should revise the way in which it conducts monetary policy cannot be fully specified in advance. Not only is there no way to prespecify how monetary policy should adapt when the economy's structure eventually changes; the assessment that such change has occurred also necessarily involves nonquantifiable judgment. ${ }^{39}$

38. This may also lead to revision of procedures and instruments on the lower levels of policy design and implementation.

39. For example, even if one uses strictly statistical criteria to detect change, the assessment of whether and when structural change has occurred depends on the choice of tests and their significance levels. Moreover, after the change has been detected, the decision concerning what the new structure might be also necessarily involves nonquantifiable judgment. For an example of such a revision process involving structural change, see Frydman and Goldberg (2007). 
Recognition of nonroutine change necessarily blurs the putatively sharp distinction between rules and discretion. As desirable as precommitment to specific targets, such as "explicit quantitative targets for some measure of medium-run inflation," might appear to be in REH models, such targets are credible for limited periods at best. Sooner or later, nonroutine change renders the monetary authority's model obsolete and thus necessitates revisions of at least some aspects of policy design.

\section{Expectations in Policy Analysis}

The 1970 Phelps volume pioneered modern macroeconomics by constructing models of aggregate outcomes on the basis of mathematical representations of individual decisionmaking. Individuals' forecasts play a key role in how they make decisions and in how markets aggregate those decisions into prices. The causal processes behind both individual decisions and aggregate outcomes, therefore, depend on market participants' understanding of the economy and how they use this knowledge to forecast the future. In the context of such models, representing how market participants might revise their forecasts in response to new policies or other changes lies at the heart of evaluating economic policies.

REH presumes that participants' forecasts of revisions following a change in policy can be adequately represented by the change in the structure of an economist's REH model. By design, REH-based policy analysis can compare only the consequences of alternative overarching rules that specify how policy is conducted in all time periods, past, present, and future.

As we noted above, Woodford argues that constraining the central bank to pre-announce commitments remains important even if one departs from REH. Seeking to provide theoretical support for this point, he discusses, in the context of the eductive and adaptive learning models of Chapters 1 and 2, the implications of the claim that market participants' expectations take into account such commitments. Woodford concludes that, for "these approaches, a comparative evaluation of alternative monetary policies will require a specification of the entire (state-contingent) future path of policy, and not simply a current action, just as in the case of REE analysis. Similarly, there will be potential benefits from commitment relative to the outcome under discretionary policy" (Chapter 13: 395)..$^{40}$

Although eductive and adaptive learning approaches depart from REH, they assume away nonroutine change by fully prespecifying how market participants revise their forecasting strategies and how aggregate outcomes

40. Woodford also examines the implications of policy commitments in his models with so-called near-rational expectations (Woodford 2010). In these models, the actual probability distribution of outcomes in all periods is presumed to be generated by an economist's REH model. Participants' "subjective beliefs [are assumed] not [to] be grossly out of line with [those] probabilities [of outcomes]” (Chapter 13: 394). 
unfold over time. In fact, even if it were feasible for officials to specify "the entire (state-contingent) future path of policy," market participants in capitalist economies are strongly motivated to search for genuinely new ways to forecast the future and deploy their resources.

The social context, including the institutions within which individuals make decisions, also changes in unforeseeable ways. But when the social context or how market participants forecast aggregate outcomes changes, so, too, does the causal process underpinning these outcomes. Policymakers and market participants understand that, even if economic policy were somehow to remain constrained to a fully predetermined path, they would face ever-imperfect knowledge of the processes driving outcomes.

Thus, even if prespecification of the entire future policy path was feasible and desirable, models that rely on mechanical rules to represent the consequences of policy changes for participants' forecasts and aggregate outcomes cannot serve as a guide for real-world policy analysis; assuming away nonroutine change does not magically eliminate its importance. Nevertheless, Woodford (Chapter 13: 395) maintains that "the argument that rule-based policymaking is necessarily foolhardy in a world where nonroutine change occurs depends on too narrow a conception of what is involved in following a rule."

By opening macroeconomic analysis to nonroutine change and everimperfect knowledge, the IKE approach presented in Chapters 4 and 6 aims to provide a theoretical underpinning for an intermediate position on rules versus discretion. In the context of financial markets, IKE suggests a policy framework that constrains officials in a qualitative way, while allowing them to exercise judgment in confronting infrequent but recurring episodes in which imperfect knowledge leads market participants to make decisions that, though individually rational, carry potentially high social costs (see Frydman and Goldberg 2009, 2011). The extent to which such suggestions may be applicable to the design and implementation of macroeconomic policy more broadly requires empirically relevant and testable models that do not fully prespecify how policymakers and market participants revise their expectations in response to nonroutine change-the hallmark of modern capitalist economies.

\section{References}

Abreu, Dilip, and Markus K. Brunnermeier. (2003) "Bubbles and Crashes," Econometrica 71: 173-204.

Aghion, Philippe, George-Marios Angelotos, Abhijit Banerjee, and Kalina Manova. (2008) "Volatility and Growth: Credit Constraints and Productivity-Enhancing Investment," NBER Working Paper 11349, National Bureau of Economic Research, Cambridge, MA. 
Bernheim, Douglas. (1984) "Rationalizable Strategic Behavior," Econometrica 52: 1007-1028.

Borrill, Paul L., and Leigh Tesfatsion. (2011) "Agent-Based Modeling: The Right Mathematics for the Social Sciences?” in J. B. Davis and D. W. Hands (eds.), Elgar Recent Economic Modeling Methodology Companion. Cheltenham, UK: Edward Elgar, pp. 228-258.

Branch, Bill, and George W. Evans. (2003) "Intrinsic Heterogeneity in Expectation Formation.” Working Paper 2003-32, Economics Department, University of Oregon, Eugene. Revised October 4, 2004.

Bray, Margaret. (1982) "Learning, Estimation and the Stability of Rational Expectations Equilibria," Journal of Economic Theory 26: 318-339.

Calvo, Guillermo A. (1983) "Staggered Prices in a Utility-Maximizing Framework," Journal of Monetary Economics 12: 383-398.

Cochrane, John H. (2009) “How Did Paul Krugman Get It So Wrong?” Mimeo. Available at: http://faculty.chicagobooth.edu/john.cochrane/research/Papers/ krugman_response.htm.

Damasio, Antonio R. (1994) Descartes' Error: Emotion, Reason, and the Human Brain. New York: Avon Books.

De Grauwe, Paul, and Marianna Grimaldi. (2006) The Exchange Rate in a Behavioral Finance Framework. Princeton, NJ: Princeton University Press.

DeLong, Bradford J., Andrei Shleifer, Lawrence H. Summers, and Robert J. Waldman. (1990) "Positive Feedback Investment Strategies and Destabilizing Rational Speculation," Journal of Finance 45: 375-395.

Engel, Charles, and James D. Hamilton. (1990) "Long Swings in the Dollar: Are They in the Data and Do Markets Know It?” American Economic Review 80: 689-713.

Evans, George W. (1983) “The Stability of Rational Expectations in Macroeconomic Models," in Roman Frydman and Edmund S. Phelps (eds.), Individual Forecasting and Aggregate Outcomes: "Rational Expectations" Examined. New York: Cambridge University Press, pp. 63-94.

Evans, George W., and Seppo Honkapohja. (2005) “An Interview with Thomas J. Sargent,” Macroeconomic Dynamics 9: 561-583.

Fischer, Stanley. (1977) "Long-Term Contracts, Rational Expectations, and the Optimal Money Supply Rule," Journal of Political Economy 85: 191-205.

Frankel, Jeffrey, and Kenneth Froot. (1987) "Understanding the U.S. Dollar in the Eighties: The Expectations of Chartists and Fundamentalists," Economic Record 62: 24-38.

Friedman, Milton. (1960) A Program for Monetary Stability. New York: Fordham University Press.

— . (1968) "The Role of Monetary Policy," American Economic Review 58: $1-17$.

Frydman, Roman. (1982) "Towards an Understanding of Market Processes: Individual Expectations, Learning and Convergence to Rational Expectations Equilibrium," American Economic Review 72: 652-668.

_ (1983) "Individual Rationality, Decentralization and the Rational Expectations Hypothesis," in Roman Frydman and Edmund S. Phelps (eds.), Individual Forecasting and Aggregate Outcomes: "Rational Expectations" Examined. New York: Cambridge University Press, pp. 97-122. 
Frydman, Roman, and Michael D. Goldberg. (2007) Imperfect Knowledge Economics: Exchange Rates and Risk. Princeton, NJ: Princeton University Press.

- . (2009) "Financial Markets and the State: Price Swings, Risk, and the Scope of Regulation," Capitalism and Society 4(2): Article 2, available at: http://www .bepress.com/cas/vol4/iss2/art2/.

- (2011) Beyond Mechanical Markets: Asset Price Swings, Risk, and the Role of the State. Princeton, NJ: Princeton University Press.

Frydman, Roman, and Edmund S. Phelps. (1983) "Introduction," in Roman Frydman and Edmund S. Phelps (eds.), Individual Forecasting and Aggregate Outcomes: "Rational Expectations" Examined. New York: Cambridge University Press, pp. 1-30.

Frydman, Roman, Katarina Juselius, Soren Johansen, and Michael D. Goldberg. (2011) "Long Swings in Currency Markets: I(2) Trends and Imperfect Knowledge." Mimeo, New York University, New York.

Frydman, Roman, Michael D. Goldberg, Soren Johansen, and Katarina Juselius. (2012) "Why REH Bubble Models Do Not Adequately Account for Swings." Mimeo, New York University, New York.

Gali, Jordi. (2008) Monetary Policy, Inflation, and the Business Cycle: An Introduction to the New Keynesian Framework. Princeton, NJ: Princeton University Press.

Goldberg, Michael D., and Roman Frydman. (1996a) "Imperfect Knowledge and Behavior in the Foreign Exchange Market," Economic Journal 106: 869-893.

_ - (1996b) "Empirical Exchange Rate Models and Shifts in the Co-Integrating Vector," Journal of Structural Change and Economic Dynamics 7: 55-78.

Guesnerie, Roger. (2005) Assessing Rational Expectations: "Eductive" Stability in Economics. Cambridge, MA: MIT Press.

Hayek, Friedrich A. (1944) The Road to Serfdom. Chicago: University of Chicago Press.

- (1948) Individualism and Economic Order. Chicago: University of Chicago Press.

—_. (1978) "The Pretence of Knowledge," 1974 Nobel lecture, in New Studies in Philosophy, Politics, Economics and the History of Ideas. Chicago: University of Chicago Press, pp. 23-34.

Hoon, Hian Teck, and Edmund S. Phelps. (1992) "Macroeconomic Shocks in a Dynamized Model of the Natural Rate of Unemployment," American Economic Review 82: 889-900.

Johansen, Soren. (1996) Likelihood Based Inference on Cointegration in the Vector Autoregressive Model. Oxford: Oxford University Press.

Juselius, Katarina. (2006) The Cointegrated VAR Model: Methodology and Applications. Oxford: Oxford University Press.

— . (2012) "The Haavelmo Probability Approach and the Cointegrated VAR." Discussion paper, Economics Department, University of Copenhagen.

Juselius, Katarina, and Javier Ordonez. (2009) "The Balassa-Samuelson Effect and the Wage, Price, and Unemployment Dynamics in Spain.” Working Paper 0529, Department of Economics, University of Copenhagen.

Kahneman, Daniel, and Amos Tversky. (1979) "Prospect Theory: An Analysis of Decision Under Risk,” Econometrica 47: 263-291. 
Keynes, John Maynard. (1921) A Treatise on Probability. London: Macmillan.

- (1936) The General Theory of Employment, Interest and Money. London: Harcourt, Brace and World.

Knight, Frank H. (1921) Risk, Uncertainty and Profit. New York: Harper.

Kydland, Finn E., and Edward C. Prescott. (1977) "Rules Rather than Discretion: The Inconsistency of Optimal Plans," Journal of Political Economy 85: 473-491.

_ (1982) "Time to Build and Aggregate Fluctuations, " Econometrica 50:13451370.

Lucas, Robert E., Jr. (1973) "Some International Evidence on Output-Inflation Trade-Offs," American Economic Review 63: 326-334.

_. (1976) "Econometric Policy Evaluation: A Critique," in Karl Brunner and Allan H. Meltzer (eds.), The Phillips Curve and Labor Markets. Carnegie-Rochester Conference Series on Public Policy. Amsterdam: North-Holland, pp. 19-46. Reprinted in Robert E. Lucas, Jr. (1981) Studies in Business-Cycle Theory. Cambridge, MA: MIT Press, pp. 104-130.

_ (1986) "Adaptive Behavior and Economic Theory," Journal of Business 59: S401-S426.

_. (1995) "The Monetary Neutrality," 1995 Nobel lecture. Available at: http:// www.nobelprize.org/nobel_prizes/economics/laureates/1995/lucas-lecture.html.

—_. (2001) "Professional Memoir." Mimeo. Available at: http://home.uchicago .edu.

- (2004) "My Keynesian Education," in Michael De Vroey and Kevin D. Hoover (eds.), The IS-LM Model: Its Rise, Fall, and Strange Persistence. Annual Supplement to volume 36 of History of Political Economy. Durham, NC: Duke University Press, pp. 12-24.

Mangee, Nicholas. (2011) "Long Swings in Stock Prices: Market Fundamentals and Psychology." PhD dissertation, University of New Hampshire, Durham.

Muth, John F. (1961) "Rational Expectations and the Theory of Price Movements," Econometrica 29: 315-335.

Obstfeld, Maurice, and Kenneth Rogoff. (1996) Foundations of International Macroeconomics. Cambridge, MA: MIT Press.

Pearce, David G. (1984) "Rationalizable Strategic Behavior and the Problem of Perfection," Econometrica 52: 1029-1050.

Phelps, Edmund S. (1968) "Money-Wage Dynamics and Labor Market Equilibrium," Journal of Political Economy 76: 678-711.

- (1969) "The New Microeconomics in Inflation and Employment Theory," American Economic Review 59(Papers and Proceedings): 147-160.

—_ (1983) "The Trouble with 'Rational Expectations' and the Problem of Inflation Stabilization," in Roman Frydman and Edmund S. Phelps (eds.), Individual Forecasting and Aggregate Outcomes: "Rational Expectations" Examined. New York: Cambridge University Press.

—_ (1994) Structural Slumps: The Modern Equilibrium Theory of Unemployment, Interest and Assets. Cambridge, MA: Harvard University Press.

—_ (1999) "Behind This Structural Boom: The Role of Asset Valuations," American Economic Review 89(Papers and Proceedings): 63-68. 
. (2006) "Prospective Shifts, Speculative Swings: 'Macro' for the Twenty-First Century in the Tradition Championed by Paul Samuelson," in M. Szenberg, L. Ramrattan, and A. A. Gottesman (eds.), Samuelsonian Economics. Oxford: Oxford University Press, pp. 66-87.

- (2007) "Foreword," in Roman Frydman and Michael D. Goldberg, Imperfect Knowledge Economics: Exchange Rates and Risk. Princeton, NJ: Princeton University Press.

Phelps, Edmund S., and John B. Taylor. (1977) "Stabilizing Powers of Monetary Policy under Rational Expectations," Journal of Political Economy 85: 163-190.

Phelps, Edmund S., and Gylfi Zoega. (1998) "Natural-Rate Theory and OECD Unemployment, “ Economic Journal 108: 782-801.

- . (2001) "Structural Booms: Productivity Explanations and Asset Valuations," Economic Policy 16: 85-126.

Phelps, Edmund S., G. C. Archibald, and Armen A. Alchian (eds.). (1970) Microeconomic Foundations of Employment and Inflation Theory. New York: W. W. Norton.

Phillips, A. W. (1958) "The Relation between Unemployment and the Rate of Change of Money Wage Rates in the United Kingdom, 1861-1957," Economica 25: 283-299.

Pigou, Arthur C. 1927. Industrial Fluctuations. London: Macmillan.

Rebelo, Sergio. (2005) "Real Business Cycle Models: Past, Present, and Future," Scandinavian Journal of Economics 107: 217-238.

Rogoff, Kenneth, and Vania Stavrakeva. (2008) "The Continuing Puzzle of Short Horizon Exchange Rate Forecasting.” NBER Working Paper 14701, National Bureau of Economic Research, Cambridge, MA.

Sargent, Thomas J. (2008) "Rational Expectations," The Concise Encyclopedia of Economics. Library of Economics and Liberty. Available at: http://www.econlib .org/library/Enc/RationalExpectations.html.

Sargent, Thomas J., and Neil Wallace. (1975) " 'Rational' Expectations, the Optimal Monetary Instrument, and the Optimal Money Supply Rule," Journal of Political Economy 83: 241-254.

Shiller, Robert J. (1981) "Do Stock Prices Move Too Much to be Justified by Subsequent Changes in Dividends?” American Economic Review 71: 421-436.

Shleifer, Andrei. (2000) Inefficient Markets. Oxford: Oxford University Press.

Sims, Christopher A. (1996) "Macroeconomics and Methodology," Journal of Economic Perspectives 10(1): 105-120.

Woodford, Michael. (2003) Interest Rates and Prices: Foundations of a Theory of Monetary Policy. Princeton, NJ: Princeton University Press.

- (2010) "Robustly Optimal Monetary Policy with Near-Rational Expectations," American Economic Review 100: 274-303. 